\title{
IMPATIENCE, INCENTIVES AND OBESITY*
}

\author{
Charles Courtemanche, Garth Heutel and Patrick McAlvanah
}

\begin{abstract}
This article explores the relationship between time preferences, economic incentives and body mass index (BMI). We provide evidence of an interaction effect between time preference and food prices, with cheaper food leading to the largest weight gains among those exhibiting the most impatience. The interaction of changing economic incentives with heterogeneous discounting may help explain why increases in BMI have been concentrated amongst the distribution's right tail. We also model time-inconsistent preferences by computing individuals' quasi-hyperbolic discounting parameters. Both long-run patience and present-bias predict BMI, suggesting obesity is partly attributable to both rational intertemporal tradeoffs and time inconsistency.
\end{abstract}

Obesity, defined as having a body mass index (BMI) of at least 30, has become a leading public health concern in the developed world in recent decades. ${ }^{1}$ The most dramatic rise has occurred in the US, where the obesity rate skyrocketed from $13 \%$ in 1960 to 34\% in 2006 (Flegal et al., 1998; National Center of Health Statistics, 2008). Adverse health conditions attributed to obesity - which include heart disease, diabetes, high blood pressure and stroke - lead to an estimated 112,000 deaths per year in the US (Sturm, 2002; Flegal et al., 2005). Treating obesity-related conditions costs the US an estimated $\$ 117$ billion annually, with about half of these expenditures financed by Medicare and Medicaid (US Department of Health and Human Services, 2001; Finkelstein et al., 2003). As shown in Figure 1, the rise in obesity has resulted from both increases in the mean and variance of BMI, as the largest weight gains have been concentrated amongst the right tail of the BMI distribution. A large literature attempts to characterise the rise in obesity as an economic phenomenon driven by changes in economic incentives, particularly falling real food prices (Philipson and Posner, 2003; Chou et al., 2004; Lakdawalla et al., 2005; Lakdawalla and Philipson, 2009; Goldman et al., 2011; Courtemanche and Carden, 2011). Aggregate trends might help explain the growth in average BMI but they cannot explain the heterogeneous nature of this growth unless some people respond more strongly to changing economic incentives than others.

Our main contribution is to provide evidence that such heterogeneity is partly attributable to differences in individuals' time preferences. We present empirical

\footnotetext{
* Corresponding author: Charles Courtemanche, Department of Economics, Andrew Young School of Policy Studies, Georgia State University, Atlanta, GA 30302, USA. Email: ccourtemanche@gsu.edu.

We thank the editor, three anonymous referees, Dan Becker, Tim Classen, Michael Grossman, Stephen Holland, Debra Holt, Pauline Ippolito, Brian Rowe, Chris Ruhm, Ken Snowden, Chris Wheeler, Erez Yoeli and Harry Zhang for helpful comments. We also thank seminar participants at the University of North Carolina at Greensboro, Yale University, Federal Trade Commission, Canadian Competition Bureau, National Bureau of Economic Research Health Economics Program Spring Meeting, International Health Economics Association World Congress and Southern Economic Association Annual Meeting for useful feedback. Will Mautz, Cody Reinhardt, Camden Sweed and Xilin Zhou provided excellent research assistance. This research was conducted using restricted data from the Bureau of Labor Statistics. The views expressed in this article do not reflect those of the BLS. We are grateful to the University of North Carolina at Greensboro for funding.

${ }^{1} \mathrm{BMI}=$ weight in kilograms divided by height in metres squared.
} 


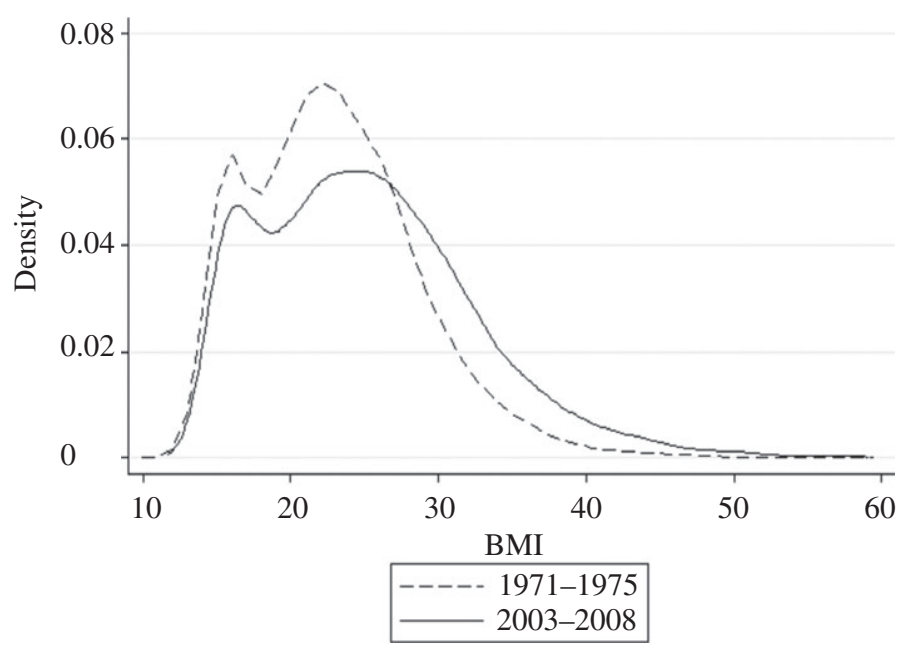

Kernel $=$ Epanechnikov, Bandwidth $=0.6955$

Fig. 1. Change in Body Mass Index (BMI) Distribution from 1971-5 to 2003-8

Notes. The 1971-5 distribution is estimated using the National Health and Nutrition Examination Survey (NHANES) I, while the 2003-8 distribution is estimated by pooling the 2003-4, 2005-6 and 2007-8 NHANES. Between 1971-5 and 2003-8, the mean of the BMI distribution rose from 23.0 to 25.3 while the SD increased from 5.9 to 7.4 .

evidence that impatient individuals (those with low discount factors) respond more strongly than do patient individuals to changes in food prices: they gain more weight when food prices fall. Less patience means relatively more emphasis on present costs such as food prices, as opposed to future costs such as the health consequences of overeating. Our second contribution is to estimate the effect of time-inconsistent preferences - quasi-hyperbolic discounting - on weight. We provide evidence that time-inconsistent preferences at least partly drive the growth in BMI and effect of food prices on BMI.

A growing body of research examines the link between time preference and BMI. ${ }^{2}$ The earliest of these studies rely on proxy variables for time preference. Komlos et al. (2004) illustrate a time-series relationship between obesity and both the savings rate and debt-to-income ratio in the US and also show that developed countries with low savings rates have higher obesity rates. Smith et al. (2005) conduct an individual-level analysis with data from the National Longitudinal Survey of Youth (NLSY), finding some evidence of a connection between savings behaviour and BMI. Borghans and Golsteyn (2006) study a Dutch data set and find that the extent to which time preference and BMI are related depends heavily on the choice of proxy. Zhang and Rashad (2008) estimate a link between time preference and BMI in two data sets, the small Roper Center Obesity survey and the larger Behavioral Risk Factor Surveillance System. Their proxies for time preference are self-reported willpower in the former and desire but no effort to lose weight in the latter.

\footnotetext{
${ }^{2}$ A related literature examines the link between risk preference and BMI; see, for instance, Anderson and Mellor (2008).
} 
More recent work utilises direct measures of time preference elicited through questions on intertemporal trade-offs. Chabris et al. (2008) find a relationship between discount rate and BMI, as well as other health behaviour such as smoking and exercise, using a sample of adults in the Boston area. Weller et al. (2008) study college students in Birmingham, AL and show that obese women exhibit greater discounting than others. Seeyave et al. (2009) use a sample of US children and find that time preference at age 4 is correlated with being overweight at age 11. Ikeda et al. (2010) estimate a connection between time preference - measured either by discount rate or a proxy variable relating to debt - and BMI among Japanese adults. Van der Pol (2011) uses a sample of Dutch adults and finds that controlling for time preference slightly attenuates the relationship between education and health outcomes such as BMI. Sutter et al. (2013) estimate a significant correlation between time preferences and $\mathrm{BMI}$, as well as alcohol and cigarette consumption, among children in Austria.

While important progress has been made in understanding the time preferenceBMI connection, two important questions remain unanswered. First, even if time preference does influence BMI, it is not clear whether this relationship can help to explain the trend in BMI as opposed to merely the level, as there is a lack of evidence that time preferences have changed as obesity has been rising. In a meta-analysis of experimental and field studies on time preferences published from 1978-2002, Percoco and Nijkamp (2009) find no evidence of changing time preferences. Borghans and Golsteyn (2006) examine trends in some of their proxy variables for time preference and find no evidence that individuals have become systematically less patient.

A second open question is the extent to which the time preference-BMI connection is the result of time-inconsistency as opposed to rational intertemporal substitution. If time-inconsistent preferences are a cause of obesity, then there is a potential economic rationale for policies designed to alter eating decisions (Cutler et al., 2003). The existing evidence that hyperbolic discounting contributes to obesity is mostly circumstantial. The National Institute of Diabetes and Digestive and Kidney Diseases (2008) notes that over 200,000 Americans a year have bariatric surgery to reduce the size of their stomachs, presumably as a commitment device to limit susceptibility to selfcontrol problems. Scharff (2009) shows that the caloric consumption of obese individuals is less responsive to nutritional information than that of other individuals, consistent with hyperbolic discounting. Ikeda et al. (2010) show that a proxy for procrastination influences BMI but do not find a statistically significant impact of their more direct measure of hyperbolic discounting - a dummy variable for whether the respondent discounted the future more heavily for a shorter delay than a longer delay. Royer et al. (2012) show that some individuals voluntarily engage in self-funded commitment contracts to exercise. Finally, Ruhm (2012) documents the high prevalence of weight loss attempts, which can be considered an admission of past mistakes resulting from time inconsistency.

We contribute to the literature on time preferences and BMI along both of these fronts using data from the 1979 cohort of the NLSY. This survey includes questions on body weight and hypothetical intertemporal trade-offs along with a rich array of other individual information that enables the construction of a detailed set of control variables. We begin by demonstrating the validity of our time preference measure and (C) 2014 Royal Economic Society. 
verifying that the connection between time preference and BMI observed in other contexts exists in our sample as well. Greater impatience is associated with higher BMI even after controlling for demographic characteristics, IQ education, work hours, occupation type, income and risk preference. The effects are strongest for whites and males. Falsification tests provide no evidence of a link between time preference and either height or health conditions that are less directly tied to eating and exercise, helping to validate the results for BMI.

We then proceed with our two main contributions. First, we match the NLSY to local price data from the Council for Community and Economic Research (C2ER) and show that the interaction of time preference and food price is a statistically significant predictor of BMI across a wide range of individual fixed effects models. Our preferred estimate implies that the food price elasticity of BMI ranges from -0.1 for the least patient individuals to statistically indistinguishable from zero among those with higher levels of patience. This interaction effect can potentially help explain why increases in BMI have been concentrated in the right tail of the distribution as food has become cheaper and more readily available. Although food prices have fallen for most consumers, their decrease has caused a larger increase in BMI for the least patient consumers, individuals who already disproportionately comprised the right tail of the BMI distribution. This heterogeneous response to decreasing food prices can help to explain trends in BMI and obesity even if individuals have not become more impatient over time. ${ }^{3}$

Second, we use responses to the NLSY's intertemporal trade-off questions to calculate each individual's quasi-hyperbolic $(\beta \delta)$ discounting parameters, decomposing time preferences into a present bias component $\beta$ and a long-run component $\delta$. We then re-run the previous BMI regressions using these two discounting parameters, finding evidence that obesity is partly attributable to both present bias and timeconsistent impatience. ${ }^{4}$ Female BMI appears more strongly driven by present-bias than time-consistent impatience, whereas the reverse is true for males. The effects of both components of time preference are stronger for whites than minorities. We also interact $\beta$ and $\delta$ with the price of food and show that both present-bias and long-run discounting strengthen price responsiveness, though only the interaction of $\beta$ with food price is consistently statistically significant.

\section{Theoretical Model}

We begin by developing a model of the roles of time preference and food prices in determining body weight. A consumer chooses food consumption $(f)$, which provides instantaneous consumption utility and affects his future weight. Our simple model provides the intuition behind the impact of prices and the discount factor on food

\footnotetext{
${ }^{3}$ Heterogeneity in food price changes could also explain some of the increasing variance of the BMI distribution. For instance, Chung and Myers (1999) provide evidence that the absence of chain stores in poor neighbourhoods Minneapolis-Saint Paul, MN increases the poor's food prices.

${ }^{4}$ In contrast to Ikeda et al. (2010), our approach accounts for not only whether individuals exhibit any present-bias but also the degree of that bias, an important distinction given that almost $85 \%$ of our sample is present-biased. The utilisation of this additional information allows us to obtain clearer results.
} 
consumption and weight. We then briefly discuss extending the model to analyse timeinconsistent preferences.

Consider a two-period model. The consumer receives an instantaneous utility from food consumption in the first period $U(f)$ and pays a per-unit price of $p$. In the following period, the consumer's weight is a function of food consumption: $w=g(f)$, where $g$ is increasing in $f$. The consumer receives a utility from his weight $V^{*}(w)$. We assume that the second-period utility is decreasing in weight, or that the consumer is at or over his ideal weight. ${ }^{5}$ To simplify the notation, define $V(f) \equiv V^{*}(w)=V^{*}[g(f)]$. First-period utility is increasing and concave in food consumption: $U^{\prime}>0, U^{\prime \prime}<0$. Second-period utility is decreasing and concave in food consumption: $V^{\prime}<0, V^{\prime \prime}<0$. The discount factor applied between the two periods is $\delta$.

The consumer's full maximisation problem is thus

$$
\max _{f} U(f)-p f+\delta V(f) .
$$

The first-order condition is

$$
U^{\prime}(f)-p+\delta V^{\prime}(f)=0 .
$$

From an additional unit of consumption, the consumer receives a marginal benefit from instantaneous utility now, pays a marginal cost now and suffers a marginal cost from weight in the future. We now show how the consumer's weight depends on the price of food $p$, the discount factor $\delta$ and how the sensitivity to price varies with the discount factor.

Intuitively, a higher food price should lead to less food consumption and thus lower weight. This can be verified by evaluating the derivative $\partial w / \partial p$ using the chain rule on $w=g(f)$ and the implicit function theorem on (2).

$$
\frac{\partial w}{\partial p}=g^{\prime}(f) \times \frac{\partial f}{\partial p}=g^{\prime}(f) \times 1 /\left[U^{\prime \prime}(f)+\delta V^{\prime \prime}(f)\right]<0 .
$$

The denominator is negative and $g^{\prime}$ is positive. Higher food prices lead to less food consumption and therefore lower weight.

Our second intuitive prediction is that more patient consumers should have lower weight, because the disutility from being overweight occurs only in the future. We evaluate $\partial w / \partial \delta$ in the same manner as above

$$
\frac{\partial w}{\partial \delta}=g^{\prime}(f) \times \frac{\partial f}{\partial \delta}=g^{\prime}(f) \times-V^{\prime}(f) /\left[U^{\prime \prime}(f)+\delta V^{\prime \prime}(f)\right]<0 .
$$

Again the denominator is negative and $g^{\prime}$ is positive. The numerator $-V^{\prime}(f)$ is positive, as we assume the consumer is above his ideal weight and thus gets negative utility from additional weight in the future. A higher discount factor indicates a more patient consumer and leads to less food consumption and lower weight.

Our third intuitive prediction is that the least patient individuals should be the most responsive to food prices. The total cost of food is the sum of the explicit monetary price, paid in the current period, and the health cost, paid in the future period.

\footnotetext{
${ }^{5}$ This is a reasonable assumption for the vast majority of our sample, as only $0.8 \%$ are underweight $(\mathrm{BMI}<18.5)$.
} 
Impatient people are relatively more concerned with present costs and therefore should be more responsive to the monetary price, that is, their $\partial w / \partial p$ should be higher in absolute value (more negative). Patient people's response to food price changes are tempered by their recognition of the future health costs. Mathematically, $\partial^{2} w / \partial \delta \partial p>0$.

To calculate this cross-partial derivative, we evaluate the derivative of $\partial w / \partial p$ with respect to $\delta$, taking care to observe that within that derivative (3), $f$ is also a function of $\delta$ and the chain rule must be applied accordingly. The cross-partial derivative is

$$
\frac{\partial^{2} w}{\partial \delta \partial p}=\left[-g^{\prime} \cdot V^{\prime \prime}-g^{\prime \prime} \cdot V^{\prime}+g^{\prime} \cdot V^{\prime} \times\left(U^{\prime \prime \prime}+\delta V^{\prime \prime \prime}\right) /\left(U^{\prime \prime}+\delta V^{\prime \prime}\right)\right] /\left[\left(U^{\prime \prime}+\delta V^{\prime \prime}\right)^{2}\right],
$$

where the arguments of the functions have been dropped for clarity. Our intuitive prediction was that this derivative should be positive, but in fact its sign is ambiguous. The coefficient in front of the brackets is positive. The first term in the brackets $\left(-g^{\prime} \cdot V^{\prime \prime}\right)$ is positive and it represents the direct intuitive effect that we described above: less patient consumers care less about the current price and therefore their weight responds less to the price. However, the two remaining terms pick up indirect effects and these may be positive or negative. The second term $\left(-g^{\prime \prime} \cdot V^{\prime}\right)$ is the same sign as $g^{\prime \prime}$, about which we make no assumptions. If $g^{\prime \prime} \geq 0$, so that food consumption increases weight either constantly or convexly, then this second term is non-negative, consistent with our intuitive prediction. Lastly, the third term in the brackets has the same sign as the numerator in the fraction, which involves third derivatives of $U$ and $V$. We make no assumptions about these third derivatives. If both are positive, as would be the case under CRRA (constant relative risk aversion) preferences or if both are zero, as would be the case under quadratic utility, then this term is non-negative and our intuition stands. However, there are possible cases in which this second derivative may in fact be negative, contrary to our intuition. ${ }^{6}$ We thus leave it to our empirical work to determine with more certainty the sign of this cross-partial derivative. A similar theoretical result is found in a model of rational addiction in Becker et al. (1991, footnote 3). They derive conditions under which relatively impatient addicts are more responsive to current prices.

This cross-partial derivative can potentially help to explain a fact about recent growth in consumers' BMI. Real food prices have fallen, which may have contributed to the growth in average BMI (3). However, prices have fallen for most consumers, yet the growth in BMI is concentrated in the right tail (Figure 1). This can be explained with two facts from our model. First, those initially among the right of the BMI distribution are likely to be those with lower discount factors (less patient), as predicted by (4). Second, if the second derivative in (5) is positive, then these impatient people will respond more strongly to the falling prices and therefore the growth in BMI will be right-skewed.

Although we will not directly test the theory that this helps to explain the rightskewed growth in BMI, we test the predictions of (3) and (4) and we test for the sign of (5). The empirical evidence supports both of our predictions and supports the claim that the second derivative is positive, consistent with our explanation for the rightskewed growth in BMI.

\footnotetext{
${ }^{6}$ By making assumptions about functional forms and parameter values, we are able to find numerically some cases where this second derivative is in fact negative, though it is positive in most cases.
} 
The two-period model provides the basic intuition and testable hypotheses regarding the interaction between food prices, discount factors and weight. It does not allow us to investigate time-inconsistent preferences, so we can consider a three-period extension of the model that allows for a consumer with quasi-hyperbolic discounting. The long run discount factor is $\delta$ and the present-bias is $\beta$. We do not present details of the model here, but they are available from the authors upon request. The model demonstrates that weight is negatively affected by food price and by both discount factors. As consumers discount the future more over the long run (lower $\delta$ ) or as consumers become more present-biased (lower $\beta$ ), food consumption and weight increase. As in the two-period model, these intuitive first-derivative results remain, whether patience is measured by the long-run discount factor or by present bias.

As with the two-period model, the cross-partial derivative of weight with respect to either $\delta$ or $\beta$ is theoretically ambiguous. Intuition suggests that as consumers become more present-focused, either because of a lower $\delta$ or because of a lower $\beta$, they should respond more strongly to price, but the expressions for both $\partial^{2} w / \partial \delta \partial p$ and $\partial^{2} w / \partial \beta \partial p$ contain a positive-definite term and other terms with ambiguous sign. As before, we turn to empirical analysis to find the sign of these effects.

For simplicity, our model ignores the quality of diet and assumes that all food has the same effect on weight. An extension to the model considers two types of food ('healthy' and 'unhealthy') with two distinct prices, only one of which affects future weight ('unhealthy' food). We show that the unhealthy food price has a negative effect on weight and the discount factor still has an unambiguously negative effect on weight. Details of this extension are available from the authors upon request.

\section{Data}

We test these intuitive and theoretical predictions using data from the NLSY, a panel from the US Bureau of Labor Statistics that follows 12,686 individuals annually from 1979 to 1994 and biennially thereafter. ${ }^{7}$ We use two different samples. The first consists of only the 2006 cross-section, as 2006 is the only year in which time preference information is available. The second (which we will refer to as the 'full sample') consists of most of the panel, starting in 1986 to match our access to price data. The 1986, 1988, 1989, 1990, 1992, 1993, 1994, 1996, 1998, 2000, 2002, 2004 and 2006 surveys include body weight, so the full sample includes 13 waves spanning 21 years. The respondents were between 14 and 22 years old at the start of the panel, making our age range 41-50 in 2006 and 21-50 in the full sample. Height is reported in 2006 and also slightly before our sample period in 1985. As all respondents were adults throughout the sample, the 1985 and 2006 heights are very similar. We use 2006 height and have verified that the results are very similar using 1985 height or the average of the two years.

\footnotetext{
7 The 12,686 respondents consist of a random sample of 6,111 plus supplemental samples of 5,295 minority and economically disadvantaged youths and 1,280 military youths. We employ the NLSY's sampling weights throughout the analysis.

${ }^{8}$ Our price data begin in 1985 , but we will be including one lag of price, which necessitates starting the sample in 1986.
} 
Our main dependent variable is BMI, which we compute from these self-reports of weight and height. Following Cawley (1999) and others, we adjust for measurement error in self-reported weight and height by exploiting the fact that another national data set, the National Health and Nutrition Examination Survey (NHANES), includes both actual and self-reported measures. Using the NHANES, we predict actual weight and height as a quadratic function of self-reported weight and height for each sex and race (white, black or another race) subgroup. We then adjust NLSY weights and heights accordingly and use the adjusted values to compute BMI. The correlation between actual and self-reported BMI is very high and the results are nearly identical if we do not employ the correction. ${ }^{9}$

Our independent variables of interest are time preference measures computed from two questions on hypothetical intertemporal trade-offs available in the 2006 NLSY survey. ${ }^{10}$ The first question is

Suppose you have won a prize of $\$ 1000$, which you can claim immediately. However, you have the alternative of waiting one year to claim the prize. If you do wait, you will receive more than $\$ 1000$. What is the smallest amount of money in addition to the $\$ 1000$ you would have to receive one year from now to convince you to wait rather than claim the prize now?

We compute respondents' discount factors - which we name 'Discount Factor 1' $(D F 1)$ - from their answers (amount 1 ) as follows:

$$
D F 1=1,000 /(1,000+\text { amount } 1) .
$$

The second question is

Suppose you have won a prize of $\$ 1000$, which you can claim immediately. However, you can choose to wait one month to claim the prize. If you do wait, you will receive more than $\$ 1000$. What is the smallest amount of money in addition to the $\$ 1000$ you would have to receive one month from now to convince you to wait rather than claim the prize now?

We use these answers (amount2) to compute annualised discount factors (via exponential annualisation) - named 'Discount Factor 2' (DF2) - through the following formula:

$$
D F 2=[1,000 /(1,000+\text { amount } 2)]^{12} .
$$

$D F 1$ is our preferred measure of time preference as it is computed directly from the question about an annual delay and thus is not subject to the compounding of

\footnotetext{
9 We use the 2005-6 NHANES wave for this correction to provide the best possible match to our 2006 sample. It is possible that using correction coefficients from 2005-6 to predict height and weight in all the years of our full sample could introduce some measurement error. However, the fact that the results are virtually identical if we do not employ the correction suggests that such out-of-sample predictions are not introducing systematic bias. It is not possible to construct an NHANES sample to span the entire time horizon of our full sample, as it did not become continuous until 1999.

${ }^{10}$ DellaVigna and Paserman (2005) utilise the NLSY (and the Panel Study of Income Dynamics) to explore the implications of impatience for job search decisions. The authors construct a measure of impatience via factor analysis of several proxies for impatience, such as smoking, life insurance and contraceptive use. Cadena and Keys (2011) use NLSY data to investigate the effects of impatience on human capital formation. Their measure of impatience comes from the survey interviewer's assessment of the subject.
} 
response error that the annualised question based on monthly delay will be. We utilise $D F 2$ as well as the average of $D F 1$ and $D F 2$ (denoted $\overline{D F}$ ) in some of the robustness checks. Our conclusions are not sensitive to the use of discount rates instead of factors. $^{11}$

We exploit the fact that the 2006 NLSY contains two intertemporal discounting questions, one over a monthly interval and the other over an annual interval, to compute a measure of present-bias. A time-consistent individual should have the same (annualised) discount factor over the monthly interval as the annual interval. By contrast, a present-biased individual will display decreasing impatience and have a greater discount factor for the annual delay than the monthly delay. We jointly fit an individual's responses to both intertemporal questions using the quasi-hyperbolic discounting specification, whereby individuals discount outcomes $\tau$ periods away at $\beta \delta^{\tau}$. The parameter $\delta$ reflects an individual's 'long-run' level of patience, whereas $\beta$ reflects any disproportionate weight given to the immediate present at the expense of all future periods (Phelps and Pollak, 1968; Laibson, 1997). If $\beta=1$, then quasihyperbolic discounting reduces to traditional, time-consistent discounting, whereas $\beta<1$ reflects time-inconsistent present-bias. Assuming annual periods, an individual's joint responses to these two questions imply that

$$
\begin{gathered}
\beta \delta^{\frac{1}{12}}=1,000 /(1,000+\text { amount } 2), \\
\beta \delta=1,000 /(1,000+\text { amount } 1),
\end{gathered}
$$

yielding $\delta=[(1,000+\text { amount } 2) /(1,000+\text { amount } 1)]^{\frac{12}{11}}$ and $\beta=1,000 /[\delta(1,000+$ amount1)].

Some economists object that hypothetical questions, such as our intertemporal discounting questions, provide no incentive for respondents to assess the intertemporal trade-off carefully and thus may not be representative of individuals' true preferences. However, at least in the domain of time preferences, several studies have demonstrated no difference in responses between real and hypothetical decisions. Johnson and Bickel (2002) and Madden et al. (2003) find no significant difference between the discounting of real versus hypothetical monetary amounts and Ubfal (2012) finds no significant difference between discounting of real versus hypothetical consumable goods as well as money. Although some studies demonstrate a difference between real and hypothetical time discounting decisions, there is no consensus over the direction of bias. Kirby and Marakovic (1995) found that subjects discounted real amounts more impatiently, whereas Coller and Williams (1999) found that respondents discounted real amounts more patiently.

Table 1 presents the correlations between each of the time preference measures from the 2006 sample. The correlation between the annual $D F 1$ and the monthly $D F 2$ is 0.58 . $D F 1$ is more closely associated with long-run patience $\delta$ whereas $D F 2$ is more closely related to present bias $\beta$. We also demonstrate the validity of the time preference questions by correlating our four time preference measures to several economic

11 Note that the discount factor computations above implicitly assume linear utility. (C) 2014 Royal Economic Society. 
Table 1

Correlation of Time Preference Measures with Intertemporal Variables

\begin{tabular}{|c|c|c|c|c|}
\hline Discount factor measure & $D F 1$ & $D F 2$ & Beta & Delta \\
\hline Annual $D F 1$ & - & - & - & - \\
\hline Monthly $D F 2$ & $\begin{array}{l}0.58 \\
(0.00)^{* * *}\end{array}$ & - & - & - \\
\hline Beta & $\begin{array}{l}0.50 \\
(0.00) * * *\end{array}$ & $\begin{array}{l}0.75 \\
(0.00) * * *\end{array}$ & - & - \\
\hline Delta & $\begin{array}{l}0.73 \\
(0.00) * * *\end{array}$ & $\begin{array}{l}0.09 \\
(0.00) * * *\end{array}$ & $\begin{array}{l}-0.13 \\
(0.00) * * *\end{array}$ & - \\
\hline High school & $\begin{array}{l}-0.06 \\
(0.00) * * *\end{array}$ & $\begin{array}{l}-0.06 \\
(0.00) * * *\end{array}$ & $\begin{array}{l}-0.08 \\
(0.00) * * *\end{array}$ & $\begin{array}{c}-0.01 \\
(0.43)\end{array}$ \\
\hline Some college & $\begin{array}{c}-0.01 \\
(0.61)\end{array}$ & $\begin{array}{r}0.002 \\
(0.84)\end{array}$ & $\begin{array}{c}0.01 \\
(0.27)\end{array}$ & $\begin{array}{c}-0.01 \\
(0.39)\end{array}$ \\
\hline College & $\begin{array}{l}0.10 \\
(0.00) * * *\end{array}$ & $\begin{array}{l}0.07 \\
(0.00) * * *\end{array}$ & $\begin{array}{l}0.11 \\
(0.00) * * *\end{array}$ & $\begin{array}{c}0.02 \\
(0.12)\end{array}$ \\
\hline AFQT & $\begin{array}{l}0.13 \\
(0.00) * * *\end{array}$ & $\begin{array}{l}0.11 \\
(0.00) * * *\end{array}$ & $\begin{array}{l}0.22 \\
(0.00) * * *\end{array}$ & $\begin{array}{c}-0.02 \\
(0.11)\end{array}$ \\
\hline Net worth & $\begin{array}{l}0.11 \\
(0.00) * * *\end{array}$ & $\begin{array}{l}0.08 \\
(0.00) * * *\end{array}$ & $\begin{array}{c}0.11 \\
(0.00) * * *\end{array}$ & $\begin{array}{l}0.03 \\
(0.01) * *\end{array}$ \\
\hline Any credit card debt & $\begin{array}{l}-0.07 \\
(0.00) * * *\end{array}$ & $\begin{array}{c}-0.02 \\
(0.12)\end{array}$ & $\begin{array}{l}-0.03 \\
(0.01) * *\end{array}$ & $\begin{array}{l}-0.03 \\
(0.01)^{* * * *}\end{array}$ \\
\hline Maxed-out credit cards & $\begin{array}{l}-0.08 \\
(0.00) * * *\end{array}$ & $\begin{array}{l}-0.07 \\
(0.00) * * *\end{array}$ & $\begin{array}{l}-0.07 \\
(0.00) * * *\end{array}$ & $\begin{array}{l}-0.03 \\
(0.01) * *\end{array}$ \\
\hline Ever declared bankrupt & $\begin{array}{l}-0.05 \\
(0.00) * * *\end{array}$ & $\begin{array}{l}-0.03 \\
(0.04) * *\end{array}$ & $\begin{array}{l}-0.03 \\
(0.01) * *\end{array}$ & $\begin{array}{c}-0.02 \\
(0.18)\end{array}$ \\
\hline Smoker & $\begin{array}{l}-0.07 \\
(0.00) * * *\end{array}$ & $\begin{array}{c}-0.02 \\
(0.11)\end{array}$ & $\begin{array}{l}-0.07 \\
(0.00) * * *\end{array}$ & $\begin{array}{l}-0.03 \\
(0.05) * *\end{array}$ \\
\hline
\end{tabular}

Notes. Pairwise correlations with p-values in parentheses. ***Statistically significant at the $1 \%$ level; **statistically significant at the $5 \%$ level; *statistically significant at the $10 \%$ level. Observations are weighted using the National Longitudinal Survey of Youth (NLSY) sampling weights. AFQT, Armed Forces Qualification Test.

variables with an obvious intertemporal component. A more patient response to the annual discounting question, $D F 1$, is correlated with more educational attainment, a greater percentile score on the Armed Forces Qualification Test (AFQT) and a greater net worth. ${ }^{12}$ Individuals with patient responses were also less likely to have any credit card debt, less likely to have maxed-out credit cards, less likely to have ever declared bankruptcy and less likely to be smokers. Our $\beta$ and $\delta$ parameters are identified from an individual's joint responses to the monthly and annual questions and one concern might be that these parameters simply reflect calculation errors. However, Table 1 reveals that the $\beta$ and $\delta$ parameters are similarly correlated with education, credit card debt, bankruptcy and smoking, which suggests that individuals' responses to these questions are not simply noise but are reflective of intertemporal preferences.

Other information available in the NLSY allows us to construct a detailed set of control variables. The demographic controls are age and dummies for gender, race and marital status. AFQT percentile proxies for intelligence. ${ }^{13}$ We measure educational

\footnotetext{
12 Net worth is computed by the NLSY based on respondents' answers to a variety of questions on income sources, assets and liabilities.

13 The AFQT is the exam taken by prospective entrants into the US military. It consists of vocabulary, reading comprehension, analytical and mathematics components. It was administered to all NLSY respondents, regardless of sex or military status, in 1985.
} 
attainment with dummy variables for high school degree but no college, some college but less than a four-year degree and college degree or higher. The omitted category is less than a high school degree. Hours worked per week and indicator variables for white collar, blue collar or service occupation (relative to the omitted category of no paid work) reflect labour market activity. ${ }^{14}$ We also control for total household income. The 2006 NLSY contains a question eliciting an individual's certainty equivalent for a $50 \%$ chance of $\$ 10,000$ and a $50 \%$ chance of nothing. In some specifications, we include an individual's response to this risk question in order to address the possible concern that time and risk preference are correlated.

The NLSY also contains a health module administered to respondents the first survey after their 40th birthdays - either 1998, 2000, 2002, 2004 or 2006. Information on chronic conditions allows for the construction of indicator variables for arthritis, anaemia, chronic kidney or bladder problems and chronic stomach problems. These dummies serve as dependent variables in the falsification tests. As these variables are only recorded once for each respondent, we only conduct the falsification tests with the cross-sectional sample.

We match these individual-level data to local price information from the C2ER's American Chamber of Commerce Researchers Association Cost of Living Index (ACCRA COLI). The ACCRA COLI computes quarterly prices for a wide range of grocery, energy, transportation, housing, health care and other items in 311 local markets throughout the US. Most of these local markets are single cities, but some are multiple cities (e.g. Bloomington-Normal, IL) while others are entire counties (e.g. Dare County, NC). We first compute annual prices for each market by averaging over all quarters in the year in which prices for the market are available. We then use the county identifiers from the restricted version of the NLSY to match each respondent in each year to the closest ACCRA COLI market. This leads to measurement error in the price variables that increases with distance from the nearest ACCRA COLI market. To mitigate potential attenuation bias, in the regressions that include prices, we drop the respondents living in counties greater than 50 miles from the closest ACCRA COLI area (approximately $11 \%$ of the sample). The conclusions reached are similar using 30 , 40, 60 and 70 mile distance cutoffs. Our food price variable is the average price of the 16 reported food items, weighted by their share as given by the ACCRA COLI. ${ }^{15}$

\footnotetext{
${ }^{14}$ We classify an individual as 'white collar' if he reports an occupation of: executive, administrative and managerial; management related; mathematical and computer scientists; engineers, architects and surveyers; engineering and related technicians; physical scientists; social scientists and related; life, physical and social science technicians; counsellors, social and religious; lawyers, judges and legal support; teachers; education, training and library; media and communications; health diagnosing and treating; health care technical and support; sales and related or office and administrative support. We classify an individual as 'blue collar' if his occupation is: entertainers and performers, sports and related; farming, fishing and forestry; construction trade and extraction; installation, maintenance and repairs; production and operating; setters, operators and tenders; transportation and material moving; military specific or armed forces. We classify an individual as 'service' if his occupation is: protective service; food preparation and serving related; cleaning and building service; entertainment attendants and related; funeral related; personal care and service; sales and related; office and administrative support or food preparation.

15 Despite the weighting, it should be noted that the food basket is not necessarily representative of average food consumption, as it is missing many important components such as dairy products, pasta and rice. Nonetheless, the ACCRA COLI provides the most appropriate price data for our analysis because of the narrow geographic level at which the data are available.
} 
The same set of weights is used for all areas. Table 2 lists these items while giving their average prices and weights. We also construct a non-food price variable by taking the weighted averages of the price indices for housing, utilities, transport, health care and miscellaneous goods and services. Additionally, in some specifications, we use separate prices for the fruit/vegetable, meat and other (generally unhealthy) food items, as denoted in Table 2.

Tables 3 and 4 report the names, descriptions, means and standard deviations for the variables that will be used in the regression analyses for the 2006 and full 19862006 samples. As the time and risk preference variables are only available in 2006, for the other years of the full sample we assign respondents their 2006 values. In other words, we assume time and risk preferences are stable across the sample period. We discuss the implications of this assumption in subsection 3.2. Similarly, AFQT score is only reported in 1985, so we assign the 1985 value to all years.

Turning to the summary statistics for the key variables, the average BMI is 28.3 in 2006 and 26.3 in the full sample. The mean discount factor is 0.6 using the annual delay question and 0.3 using the monthly delay question, corresponding to a $66 \%$ and $257 \%$ annual interest rate. Though this degree of financial impatience may appear implausibly high, note that the NLSY questions explicitly establish receiving money immediately as the status quo. A robust finding is that preferences are sticky towards a status quo option and measuring patience via this willingness to delay methodology yields greater elicited impatience than methods which do not impose an immediate intertemporal reference point (Loewenstein, 1988; Shelley, 1993; McAlvanah, 2010). The average respondent is more patient over longer delays,

Table 2

ACCRA COLI Food Items (2006)

\begin{tabular}{|c|c|c|}
\hline Item & $\begin{array}{c}\text { Average } \\
\text { price }\end{array}$ & Weight \\
\hline \multicolumn{3}{|l|}{ Fruits and vegetables } \\
\hline $\begin{array}{l}\text { Head of iceberg lettuce } \\
1 \mathrm{lb} \text {. bananas } \\
10 \mathrm{lb} \text {. sack potatoes } \\
15 \mathrm{oz} \text {. can sweet peas; Del Monte or Green Giant } \\
29 \mathrm{oz} \text {. halves or slices peaches; Hunts, Del Monte, or Libby's } \\
16 \mathrm{oz} \text {. whole kernel frozen corn }\end{array}$ & $\begin{array}{l}1.219 \\
0.518 \\
3.753 \\
0.826 \\
1.805 \\
1.240\end{array}$ & $\begin{array}{l}0.0267 \\
0.0555 \\
0.0264 \\
0.0110 \\
0.0127 \\
0.0110\end{array}$ \\
\hline $\begin{array}{l}\text { Meats } \\
1 \text { lb. t-bone steak } \\
1 \text { lb. ground beef } \\
1 \text { lb. whole uncut chicken } \\
\text { Dozen large eggs; grade A or AA } \\
6 \text { oz. chunk of light tuna; Starkist or Chicken of the Sea }\end{array}$ & $\begin{array}{l}8.383 \\
2.539 \\
1.057 \\
1.150 \\
0.746\end{array}$ & $\begin{array}{l}0.0354 \\
0.0354 \\
0.0440 \\
0.0100 \\
0.0378\end{array}$ \\
\hline $\begin{array}{l}\text { Other foods } \\
24 \mathrm{oz} \text {. white bread } \\
18 \mathrm{oz} \text {. box of corn flakes; Kellogg's or Post } \\
1 / 4 \mathrm{lb} \text {. patty with cheese; McDonald's } \\
11^{\prime \prime} \text { to } 12^{\prime \prime} \text { thin crust cheese pizza; Pizza Hut or Pizza Inn } \\
\text { Thigh and drumstick of chicken; Kentucky Fried Chicken or Church's }\end{array}$ & $\begin{array}{r}1.175 \\
2.987 \\
2.549 \\
10.250 \\
2.863\end{array}$ & $\begin{array}{l}0.0861 \\
0.0399 \\
0.1133 \\
0.1133 \\
0.1133\end{array}$ \\
\hline
\end{tabular}

(C) 2014 Royal Economic Society. 
Table 3

Summary Statistics for BMI, Time Preference, and Food Price Variables

\begin{tabular}{|c|c|c|c|}
\hline \multirow[b]{2}{*}{ Variable name } & \multirow[b]{2}{*}{ Description } & \multicolumn{2}{|c|}{ Mean (SD) } \\
\hline & & 2006 & Full \\
\hline BMI & Body mass index $\left(\mathrm{kg} / \mathrm{m}^{2}\right)$ & $\begin{array}{l}28.26 \\
(5.76)\end{array}$ & $\begin{array}{l}26.31 \\
(5.43)\end{array}$ \\
\hline Beta & Computed using quasi-hyperbolic discounting specification & $\begin{array}{c}0.80 \\
(0.20)\end{array}$ & $\begin{array}{c}0.80 \\
(0.20)\end{array}$ \\
\hline Delta & Computed using quasi-hyperbolic discounting specification & $\begin{array}{c}0.75 \\
(0.33)\end{array}$ & $\begin{array}{c}0.75 \\
(0.33)\end{array}$ \\
\hline Discount factor 1 & Based on amount needed to wait a year to receive $\$ 1,000$ & $\begin{array}{c}0.59 \\
(0.25)\end{array}$ & $\begin{array}{c}0.59 \\
(0.26)\end{array}$ \\
\hline Discount factor 2 & Based on amount needed to wait a month to receive $\$ 1,000$ & $\begin{array}{c}0.28 \\
(0.34)\end{array}$ & $\begin{array}{c}0.28 \\
(0.34)\end{array}$ \\
\hline Food price & Weighted average price of 16 food items $(2006 \$)$ & $\begin{array}{c}3.53 \\
(0.28)\end{array}$ & $\begin{array}{c}3.69 \\
(0.38)\end{array}$ \\
\hline Non-food index & Weighted average price index of non-food price categories & $\begin{array}{l}106.01 \\
(18.64)\end{array}$ & $\begin{array}{c}109.24 \\
(22.69)\end{array}$ \\
\hline Fruit/vegetable price & Weighted average price of six fruits/vegetables $(2006 \$)$ & $\begin{array}{c}1.47 \\
(0.20)\end{array}$ & $\begin{array}{c}1.51 \\
(0.23)\end{array}$ \\
\hline Meat price & Weighted average price of five grocery meats $(2006 \$)$ & $\begin{array}{c}2.94 \\
(1.30)\end{array}$ & $\begin{array}{c}3.04 \\
(0.34)\end{array}$ \\
\hline Other food price & Weighted average price of five other foods $(2006 \$)$ & $\begin{array}{c}4.64 \\
(0.39)\end{array}$ & $\begin{array}{c}4.31 \\
(0.35)\end{array}$ \\
\hline
\end{tabular}

Notes. Observations are weighted using the National Longitudinal Survey of Youth (NLSY) sampling weights. $n=5,982$ in the 2006 analysis sample, and 63,950 in the 1986-2006 analysis sample. SD, standard deviation.

supportive of hyperbolic discounting or diminishing impatience. The quasi-hyperbolic specification implies that the average individual discounts any future outcome with $\beta$ equal to 0.80 and subsequent periods with discount factor of 0.75 or about $33 \%$ per year. The inclusion of $\beta$ implies a more patient level of annual discounting than the prior specifications. Eighty-five per cent of individuals have $\beta<1$, indicating that the vast majority of respondents are present-biased. Seven per cent of respondents reported perfect patience on both questions and are therefore exactly time-consistent with $\beta=1.8 \%$ of respondents are hyperopic and future-biased with $\beta>1$. This asymmetry of $\beta$ about one suggests that this variable is not merely representing noise from subjects' misreporting.

The average inflation-adjusted price of the basket of 16 foods is $\$ 3.69$ in the full 1986-2006 sample. There is substantial time-series and cross-sectional variation in food price in our sample. Food prices fell for $87 \%$ of respondents during the sample period, with average price dropping from $\$ 3.91$ in 1986 to $\$ 3.53$ in 2006 . The range of food prices observed in the average year is $\$ 2.16$ or a sizeable $59 \%$ of the mean. There is also considerable within-individual variation in food price, as the correlation between current food price and its first lag is only 0.61 in the full sample. ${ }^{16}$

\footnotetext{
16 The data - excluding the restricted state and county identifiers - and Stata .do files used in the article are available in the online Appendix.
} 
Table 4

Summary Statistics for Control and Falsification Test Variables

\begin{tabular}{|c|c|c|c|}
\hline \multirow[b]{2}{*}{ Variable name } & \multirow[b]{2}{*}{ Description } & \multicolumn{2}{|c|}{ Mean (SD) } \\
\hline & & 2006 & Full \\
\hline Age & Age in years & $\begin{array}{l}44.87 \\
(2.230)\end{array}$ & $\begin{array}{l}34.47 \\
(6.59)\end{array}$ \\
\hline Female & 1 if female & $\begin{array}{c}0.48 \\
(0.50)\end{array}$ & $\begin{array}{c}0.48 \\
(0.50)\end{array}$ \\
\hline Race: black & 1 if race is black & $\begin{array}{c}0.13 \\
(0.34)\end{array}$ & $\begin{array}{c}0.14 \\
(0.34)\end{array}$ \\
\hline Race: other & 1 if race is neither black nor white & $\begin{array}{c}0.03 \\
(0.16)\end{array}$ & $\begin{array}{c}0.02 \\
(0.16)\end{array}$ \\
\hline Married & 1 if married & $\begin{array}{c}0.64 \\
(0.48)\end{array}$ & $\begin{array}{c}0.60 \\
(0.49)\end{array}$ \\
\hline AFQT & Percentile score on armed forces qualifying test in 1985 & $\begin{array}{c}48.97 \\
(28.54)\end{array}$ & $\begin{array}{c}49.19 \\
(28.66)\end{array}$ \\
\hline High school & 1 if highest grade completed $=12$ & $\begin{array}{c}0.41 \\
(0.49)\end{array}$ & $\begin{array}{c}0.42 \\
(0.49)\end{array}$ \\
\hline Some college & 1 if $13 \leq$ highest grade completed $\leq 15$ & $\begin{array}{c}0.24 \\
(0.42)\end{array}$ & $\begin{array}{c}0.23 \\
(0.42)\end{array}$ \\
\hline College & 1 if highest grade completed $\geq 16$ & $\begin{array}{c}0.28 \\
(0.45)\end{array}$ & $\begin{array}{c}0.26 \\
(0.44)\end{array}$ \\
\hline White collar & 1 if current occupation is white collar & $\begin{array}{c}0.56 \\
(0.50)\end{array}$ & $\begin{array}{c}0.52 \\
(0.50)\end{array}$ \\
\hline Blue collar & 1 if current occupation is blue collar & $\begin{array}{l}(0.42) \\
(0.42)\end{array}$ & $\begin{array}{c}0.28 \\
(0.45)\end{array}$ \\
\hline Service & 1 if current occupation is service & $\begin{array}{c}0.10 \\
(0.30)\end{array}$ & $\begin{array}{c}0.11 \\
(0.31)\end{array}$ \\
\hline Hours worked & Average hours worked per week in the preceding year & $\begin{array}{c}35.92 \\
(19.40)\end{array}$ & $\begin{array}{c}35.27 \\
(18.69)\end{array}$ \\
\hline Income & Total household income $(\$ 10,000 \mathrm{~s} ; 2006 \$)$ & $\begin{array}{c}8.31 \\
(8.41)\end{array}$ & $\begin{array}{c}7.33 \\
(11.77)\end{array}$ \\
\hline Risk & Amount $(\$ 1,000 \mathrm{~s})$ to forego a $50 \%$ chance of $\$ 10,000$ or $\$ 0$ & $\begin{array}{c}4.79 \\
(3.27)\end{array}$ & $\begin{array}{c}4.79 \\
(3.26)\end{array}$ \\
\hline Arthritis & 1 if ever had arthritis or rheumatism & $\begin{array}{c}0.12 \\
(0.32)\end{array}$ & - \\
\hline Kidney/bladder & 1 if kidney or bladder problems & $\begin{array}{c}0.05 \\
(0.21)\end{array}$ & - \\
\hline Stomach & 1 if trouble with stomach, liver, intestines or gall bladder & $\begin{array}{c}0.10 \\
(0.30)\end{array}$ & - \\
\hline Anaemia & 1 if anaemic & $\begin{array}{c}0.04 \\
(0.21)\end{array}$ & - \\
\hline
\end{tabular}

Notes. -, indicates these variables are not used in the 1986-2006 sample. AFQT, Armed Forces Qualification Test. For other notes see Table 3.

\section{Empirical Analysis}

\subsection{Discount Factor and BMI}

The two main objectives of this article are to examine the interaction effect of time preference and food price on BMI and to test whether the effect of time preference on BMI is driven by time-consistent patience or present-bias. Before turning to these questions, it is important to verify that the previously-documented connection between time preference and BMI exists in our sample. We therefore begin by estimating the (C) 2014 Royal Economic Society. 
association between discount factor and BMI using the 2006 sample and conducting falsification tests to assess the validity of the results. Our main regression equation is

$$
B M I_{i}=\alpha_{0}+\alpha_{1} D F 1_{i}+\alpha_{2} \mathbf{X}_{i}+\varepsilon_{i},
$$

where $i$ indexes individuals. ${ }^{17} D F 1$ is the preferred annual discount factor measure described in Section 2. $\mathbf{X}$ is a vector of controls that includes five distinct categories of variables. First are the demographic characteristics: age and indicators for gender, race and marital status. Second are variables reflecting endowment of and investment in human capital: AFQT score and dummies for educational attainment. The third category consists of controls for labour market activity, including work hours and indicators for whether an individual's employment is blue-collar, white-collar or service industry, relative to the omitted category of unemployment. Next, the income category consists of real income and its square as prior research has documented an inverted U-shaped relationship between income and BMI (Lakdawalla and Philipson, 2009). Finally, we include the variable for risk preference. We include the control variables in an effort to isolate the ceteris paribus relationship between time preference and BMI. If levels of patience and BMI both differ systematically on the basis of age, gender, race, marital status, intelligence, education, income, time spent working or risk preference, failing to adequately control for these variables may bias the estimators of $\alpha_{1}{ }^{18}$

Table 5 reports the key results; full regression output is available upon request. We begin in column (1) with a simple regression of BMI on discount factor and then gradually add the categories of controls to build up to the full model in column (6). As robustness checks, in columns (7) and (8) we replace $D F 1$ with $D F 2$ and $\overline{D F}$, respectively. Discount factor is statistically significant and negatively associated with BMI in all eight regressions, suggesting that greater patience decreases weight. Including the demographic and human capital controls in columns (2) and (3) attenuates the coefficient estimate for $\alpha_{1}$ somewhat, but across columns (3) to (6) the effect stabilises at -0.97 to -1.08 units. The results from columns (3) to (6) imply that a one standard deviation increase in discount factor (0.25) decreases BMI by an average of $0.24-0.27$ units or $1.6-1.8$ pounds at the sample mean height of 67.55 inches. Columns (7) and (8) show that the results are similar using the alternative discount factor measures. Though we are of course unable to control for every

\footnotetext{
${ }^{17}$ In an unreported regression (full results available upon request), we use BMI category rather than BMI as the outcome variable and estimate an ordered probit model. The categories are healthy weight $(\mathrm{BMI}<25)$, overweight but not obese $(25 \leq \mathrm{BMI}<30)$, class I obese $(30 \leq \mathrm{BMI}<35)$ and severely obese $(\mathrm{BMI} \geq 35)$. The marginal effect of discount factor on $\mathrm{P}$ (overweight but not obese) is small and insignificant, but the marginal effects of discount factor on $\mathrm{P}$ (class I obese) and $\mathrm{P}$ (severely obese) are -0.027 and -0.033 and are significant at the $5 \%$ level.

${ }^{18}$ We do not control for some of the variables shown to be correlated with discount factor in Table 1 - net worth, credit card debt, maxed-out credit cards, bankruptcy and smoking - because in our judgment the literature strongly suggests that they are causally affected by time preference. Including them could therefore lead to an over controlling problem in which we 'control away' some of the mechanisms through which time preference causally affects BMI. In unreported regressions, we do control for these variables and they only slightly attenuate the association between discount factor and BMI. Less obvious over controlling problems could also exist for some of the variables we do include in the reported regressions, such as AFQT score, education, work hours and income. This highlights the importance of showing that the estimated effect of discount factor remains similar across a number of specifications with different combinations of control variables.
} 
Table 5

Discount Factor and Body Mass Index (BMI)

\begin{tabular}{|c|c|c|c|c|c|c|c|c|}
\hline & (1) & (2) & (3) & (4) & (5) & (6) & (7) & (8) \\
\hline \multicolumn{9}{|c|}{ Dependent variable: $B M I$} \\
\hline Discount factor & $\begin{array}{l}-1.44 \\
(0.35) * * *\end{array}$ & $\begin{array}{l}-1.30 \\
(0.35) * * *\end{array}$ & $\begin{array}{l}-1.08 \\
(0.35)^{* *}\end{array}$ & $\begin{array}{l}-1.07 \\
(0.35) * * *\end{array}$ & $\begin{array}{l}-0.97 \\
(0.35) * * *\end{array}$ & $\begin{array}{l}-1.02 \\
(0.35) * * *\end{array}$ & $\begin{array}{l}-0.87 \\
(0.26) * * *\end{array}$ & $\begin{array}{l}-1.20 \\
(0.34) * * *\end{array}$ \\
\hline Demographics & No & Yes & Yes & Yes & Yes & Yes & Yes & Yes \\
\hline Human capital & No & No & Yes & Yes & Yes & Yes & Yes & Yes \\
\hline Labour & No & No & No & Yes & Yes & Yes & Yes & Yes \\
\hline Income & No & No & No & No & Yes & Yes & Yes & Yes \\
\hline Risk & No & No & No & No & No & Yes & Yes & Yes \\
\hline $\begin{array}{l}\text { Discount factor } \\
\text { measure }\end{array}$ & $D F 1$ & $D F 1$ & $D F 1$ & $D F 1$ & $D F 1$ & $D F 1$ & $D F 2$ & $\overline{D F}$ \\
\hline Observations & 5,982 & 5,982 & 5,982 & 5,982 & 5,982 & 5,982 & 5,982 & 5,982 \\
\hline
\end{tabular}

Notes. Heteroscedasticity-robust standard errors in parentheses. ***Statistically significant at $1 \%$ level; **statistically significant at $5 \%$ level; *statistically significant at $10 \%$ level. Observations are weighted using the National Longitudinal Survey of Youth (NLSY) sampling weights. 'Demographic' controls include age, gender, race and marital status. 'Human capital' controls include Armed Forces Qualification Test (AFQT) score and the education dummies. 'Labour' controls include work hours and white collar, blue collar and service indicators. 'Income' controls include income and income ${ }^{2}$. 'Risk' control is the measure of risk preference.

potential confounding factor, the robustness of the link between discount factor and BMI increases our confidence that the relationship is causal rather than spurious.

Table 6 displays the estimates of $\alpha_{1}$ splitting the sample by gender and race, using $D F 1$ and the full set of control variables. The effect of discount factor on BMI is strong and significant for men and still negative but smaller and slightly insignificant for women. ${ }^{19}$ When stratifying by race, discount factor's impact is strong and significant for whites but small and insignificant for non-whites.

We close this subsection with a series of falsification tests. First, we re-estimate (10) using height in inches instead of BMI as the dependent variable. As it is implausible that impatience affects BMI by making people shorter rather than increasing their weight, such a finding would call into question the validity of the identification strategy. We then utilise as dependent variables, chronic health conditions that are less directly the result of intertemporal choices than BMI: arthritis or rheumatism; kidney or bladder problems; stomach, liver, intestinal or gall bladder problems and anaemia. We also consider a dependent variable representing the total number of these conditions reported. While it is difficult to find health outcomes that are completely independent of health behaviour, we expect that these conditions should at least be less directly tied to behaviour than obesity. A large 'effect' of discount factor on these outcomes would therefore suggest a mis-specified model rather than a causal effect.

19 Ikeda et al. (2010) provide similar findings. In their regressions (from data on a Japanese subject pool), the coefficient on the discount rate is larger for males than for females, though not significantly so in the regressions with demographic controls. Without demographic controls, the coefficient for males is about twice as high as that for females and only the coefficient on males is significant. While we are unsure why the connection between time preference and BMI is stronger for men than women, the fact that similar results have been found in Japan suggests that cultural factors unique to the US do not provide a sufficient explanation. 
Table 6

Heterogeneity by Gender and Race

\begin{tabular}{|c|c|c|c|c|}
\hline & \multicolumn{2}{|c|}{ Gender } & \multicolumn{2}{|c|}{ Race } \\
\hline & Women & Men & White & Non-white \\
\hline \multicolumn{5}{|c|}{ Dependent variable: body mass index } \\
\hline Discount factor & $\begin{array}{c}-0.74 \\
(0.50)\end{array}$ & $\begin{array}{l}-1.36 \\
(0.49) * * *\end{array}$ & $\begin{array}{l}-1.17 \\
(0.41) * * *\end{array}$ & $\begin{array}{c}-0.22 \\
(0.54)\end{array}$ \\
\hline Demographics & Yes & Yes & Yes & Yes \\
\hline Human capital & Yes & Yes & Yes & Yes \\
\hline Labour & Yes & Yes & Yes & Yes \\
\hline Income & Yes & Yes & Yes & Yes \\
\hline Risk & Yes & Yes & Yes & Yes \\
\hline Discount factor measure & $D F 1$ & $D F 1$ & $D F 1$ & $D F 1$ \\
\hline Observations & 2,989 & 2,993 & 3,894 & 2,088 \\
\hline
\end{tabular}

Notes. For notes see Table 5.

Table 7

Falsification Tests Using Various Health Conditions

\begin{tabular}{lcccccc}
\hline \hline & Height & Arthritis & $\begin{array}{l}\text { Kidney/ } \\
\text { bladder }\end{array}$ & Stomach & Anaemia & $\begin{array}{c}\text { Number of } \\
\text { conditions }\end{array}$ \\
\hline Dependent variables & & & & & & \\
Discount factor & -0.15 & 0.015 & 0.011 & -0.012 & -0.004 & 0.003 \\
& $(0.16)$ & $(0.019)$ & $(0.010)$ & $(0.017)$ & $(0.008)$ & $(0.032)$ \\
Demographics & Yes & Yes & Yes & Yes & Yes & Yes \\
Human capital & Yes & Yes & Yes & Yes & Yes & Yes \\
Labour & Yes & Yes & Yes & Yes & Yes & Yes \\
Income & Yes & Yes & Yes & Yes & Yes & Yes \\
Risk & Yes & Yes & Yes & Yes & Yes & Yes \\
Discount factor measure & $D F 1$ & $D F 1$ & $D F 1$ & $D F 1$ & $D F 1$ & $D F 1$ \\
Observations & 5,982 & 5,975 & 5,971 & 5,970 & 5,970 & 5,952 \\
\hline \hline
\end{tabular}

Notes. Marginal effects reported in all regressions. For other notes see Table 5.

We estimate linear models for height, probit models for the individual health conditions and a Poisson model for the total number of conditions. Table 7 reports the marginal effects. Discount factor is never significant at even the $10 \%$ level. These results increase our confidence that the findings for BMI are not the artifact of omitted variables correlated with patience and either health or stature. The falsification tests also help alleviate concerns about reverse causality, as having a high BMI might decrease an individual's life expectancy and thereby cause him to optimise over a shorter time horizon. If this were the case, the measured discount factor should be correlated with all health problems regardless of whether they are the direct result of behaviours.

\subsection{Interaction of Discount Factor and Food Prices}

We next test the prediction that impatience strengthens the response to food prices by examining heterogeneity in the effect of local food prices on BMI on the basis of (C) 2014 Royal Economic Society. 
discount factor. Food prices are perhaps the most obvious economic incentive related to body weight and the decline in real food prices in recent decades is generally regarded as a contributing factor to the rise in obesity (Philipson and Posner, 2003; Chou et al., 2004; Lakdawalla and Philipson, 2009; Goldman et al., 2011). Changing economic incentives such as falling food prices may explain the increase in the mean of the BMI distribution but do not explain why the variance of the distribution has also increased. We hypothesise that changing incentives have interacted with individuals' levels of patience to both shift the BMI distribution to the right and thicken its right tail. Testing for an effect of the interaction of discount factor and food prices provides a preliminary test of this theory.

We incorporate local food prices, non-food prices and the interaction of food prices with discount factors into our analysis. Our theoretical framework treats weight as a function of food prices in the prior period, as weight is a capital stock that is determined by past eating 'investments' and Goldman et al. (2011) provide evidence that the long-run effect of food prices on BMI is stronger than the short-run effect. Because of the inherently dynamic relationship between food prices and weight gain, we employ a specification that utilises the full sample of 1986-2006. The panel nature of the NLSY allows for the inclusion of individual fixed effects to control for unobservable characteristics that are stable over time. The identifying assumption for the food price effect therefore becomes merely that changes over time in unobservable determinants of BMI are uncorrelated with changes over time in food prices. ${ }^{20}$ It also allows for the matching of individuals to lagged food prices without having to impose the assumption that people remain in the same county over time.

Given that we only observe an individual's time preference in 2006, a panel specification requires the assumption that time preferences are stable across the entire period. Some evidence suggests that time preferences are relatively stable within an individual. Simpson and Vuchinich (2000) demonstrate a high test-retest reliability for time preferences measured in laboratory experiments and Meier and Sprenger (2010) find a similar high degree of stability for time preferences in a longitudinal field experiment. In both of these studies, the within-person stability of time preference was similar to those of personality traits. Moreover, even if time preferences do change within individuals, this measurement error would lead to attenuation bias that would cause us to underestimate the interaction effect of time preference and food prices. In other words, the results from the panel regressions can perhaps be viewed as conservative. ${ }^{21}$

Our panel specification adds local food prices $(P F O O D)$, non-food prices $(P N F)$ and the interaction of food prices with the discount factor. Controlling for non-food prices helps ensure that the estimated effect of food price is not simply capturing a more general price effect. We also include individual and year fixed effects, while dropping

\footnotetext{
${ }^{20}$ Results (available upon request) are similar if we include both individual and county fixed effects, though the estimates are slightly less precise. This is not surprising, as county fixed effects only provide new information for people who move during the sample period.

${ }^{21}$ To address any concern with our assumption that time preferences are stable throughout the sample period, in unreported regressions we ran cross-sectional regressions examining the interaction of food prices and discount factor using solely the 2006 sample. The estimates from the fixed effects panel regressions are smaller in magnitude than those from the cross-sectional regressions but always within the $95 \%$ confidence interval.
} 
the time-invariant covariates discount factor, risk preference, AFQT score, race and gender. Importantly, the interaction of discount factor with food price does not drop out of the model, as food price varies over time. We experimented with different lag lengths, finding that the first lag of food price and the interaction of food price with discount factor were consistently significant but that second, third or fourth lags were consistently insignificant. We therefore include one lag of food price and the interaction term in the model. We also add one lag of each of the controls to guard against bias from lagged price being correlated with lagged controls. ${ }^{22}$ The resulting regression equation is

$$
\begin{aligned}
\mathrm{BMI}_{i c t}= & \alpha_{0}+\boldsymbol{\alpha}_{11} \mathbf{X}_{i c t}+\boldsymbol{\alpha}_{12} \mathbf{X}_{i c, t-1}+\alpha_{21} \text { PFOOD }_{c t}+\alpha_{22} \text { PFOOD }_{c, t-1} \\
& +\alpha_{31}\left(D F 1_{i c} \times P F O O D_{c t}\right)+\alpha_{32}\left(D F 1_{i c} \times P F O O D_{c, t-1}\right)+\alpha_{41} P N F_{c t} \\
& +\alpha_{42} P N F_{c, t-1}+\mu_{i}+\tau_{t}+\varepsilon_{i c t},
\end{aligned}
$$

where $c$ indexes counties, $t$ denotes survey year, $\mathbf{X}$ excludes the gender and race dummies and AFQT score and $\mu_{i}$ and $\tau_{t}$ are the individual and year fixed effects. Of particular interest are the 'total effects' of food price and the interaction of discount factor with food price. These are simply the sum of the contemporaneous and lagged effects: $\alpha_{21}+\alpha_{22}$ and $\alpha_{31}+\alpha_{32}$, respectively. Because of the addition of county-level variables, we now cluster standard errors by county. Our model assumes that the effect of food price on BMI changes linearly across the discount factor distribution. We have also estimated models using a quadratic functional form for discount factor, as well as a series of dummies splitting the discount factor distribution into thirds and fifths. We did not observe clear evidence of non-linearities, so we present the results from the simple linear specification.

Table 8 reports the results from the fixed effects regressions, gradually adding controls up to the full model in column (5), with columns (6) and (7) utilising the alternative discount factor measures. ${ }^{23}$ All 14 coefficient estimates for food price and lagged food price are negative and 13 of the 14 are significant. Consistent with the intertemporal nature of our theoretical framework, lagged food price appears to have about twice as strong an effect on BMI as contemporaneous food price. All 14 coefficient estimates for the interaction term and the lagged interaction term are positive and significant, with the lagged interaction of discount factor with food price having roughly twice as strong an effect on BMI as the contemporaneous interaction. Turning to the total effects, the 'total food price effect' is always significant at the $5 \%$ level or better while the 'total interaction effect' is always significant at the $1 \%$ level. In summary, these regressions reveal that the effect of food price on BMI is strongest for impatient individuals.

\subsubsection{Simulations}

Figure 2 uses the estimates from the fixed effects model with the full set of controls (column (5) of Table 8) to show how the marginal effect of food price on BMI changes

\footnotetext{
${ }^{22}$ Recall that our full sample consists of 13 waves spanning 21 years. The average lag length is therefore approximately 1.6 years, with some lags being one year and others being two years.

Table 9 has one less column than Table 8 because risk preference is dropped from the model as it is time invariant in our data.
} 


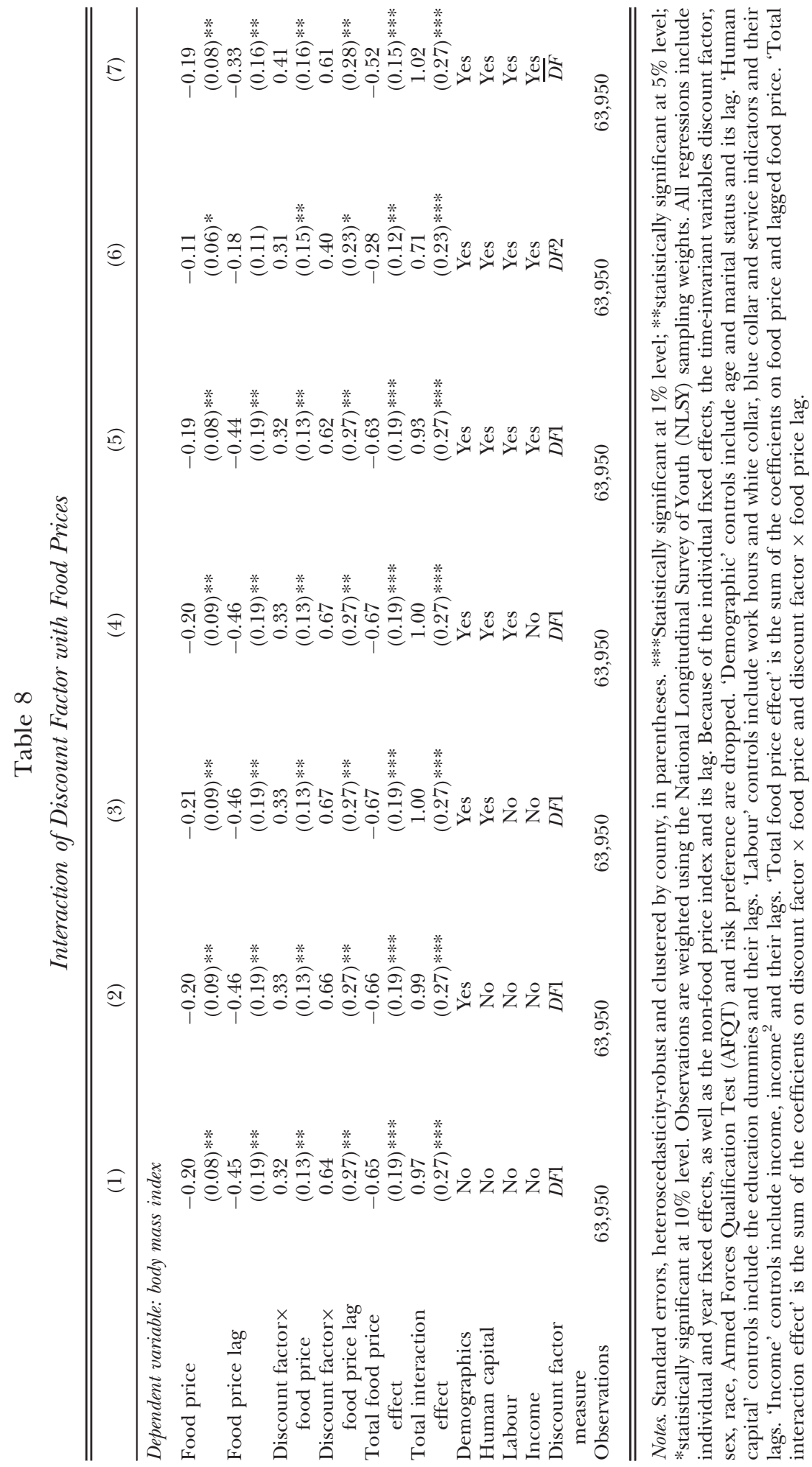

(C) 2014 Royal Economic Society. 


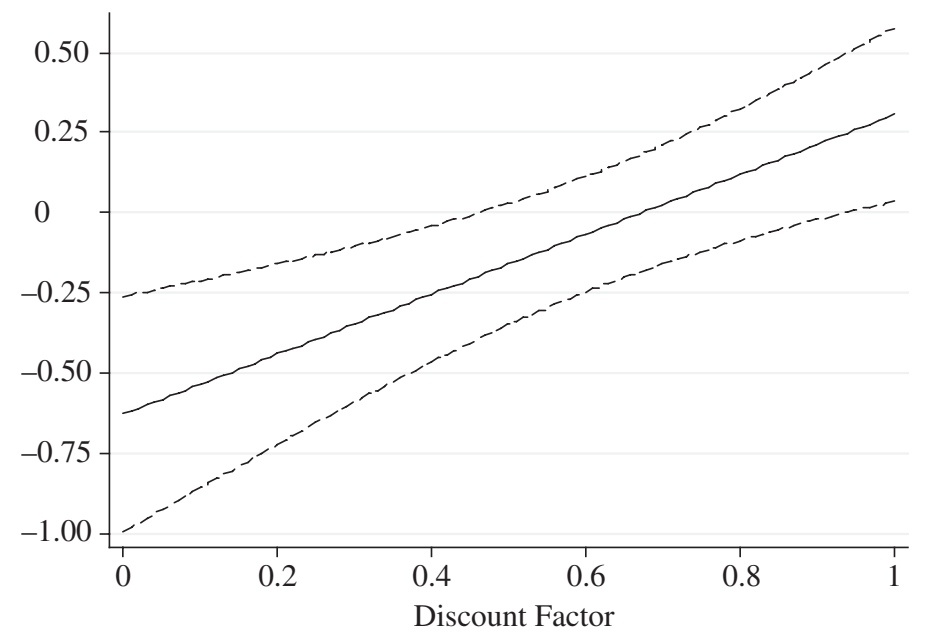

Fig. 2. Marginal Effect of Food Price on Body Mass Index (BMI) Across Discount Factor Distribution Note. Solid line represents point estimate; dashed lines represent endpoints of $95 \%$ confidence interval.

across the discount factor distribution. The solid line shows the marginal effect, while the dashed lines represent the endpoints of the $95 \%$ confidence interval. A $\$ 1$ increase in food price (27\% of the sample mean) decreases the BMIs of the most impatient individuals by 0.6 units or 4 pounds at the sample mean height. This is a decrease of $2.3 \%$ of the sample mean BMI, implying a food price elasticity of BMI of -0.1 . The effect of food prices on BMI steadily weakens with additional patience, reaching zero at a discount factor of 0.69 . Though the sign flips to positive after that point, the marginal effect does not become positive and significant at the $5 \%$ level until the very top of the discount factor distribution.

Figures 3-5 illustrate how this heterogeneity in the food price effect can affect the variance of the BMI distribution. We perform an approximate median split and define 'impatient' individuals as those with discount factors below 0.5 and 'patient' individuals as those with discount factors above 0.5. We use the regression results from the fixed effects model in column (5) of Table 8 to plot the predicted BMI distributions for the two groups at the approximate high end of the food price range observed in our full sample $(\$ 5.50)$, the approximate low end of this range $(\$ 2.50)$ and the midpoint of this range $(\$ 4.00) .{ }^{24}$ Below the figures, we also report the mean BMI, percentage overweight or obese $(\mathrm{BMI} \geq 25)$, percentage obese $(\mathrm{BMI} \geq 30)$ and percentage severely obese $(B M I \geq 35)$ for the impatient and patient groups at each price point. Figure 3 shows that at a relatively high food price, the BMI distributions of patient and impatient individuals are very similar, as are their mean BMIs and rates of being in unhealthy weight categories. Figure 4 shows that at a medium food price a gap

\footnotetext{
24 Predicted BMI is computed simply by adding to actual BMI the difference between simulated $(\$ 5.50, \$ 4$, or $\$ 2.50$ ) and actual food price times the coefficient estimate for food price and the difference between the interaction term at the simulated and actual food price times the coefficient estimate for the interaction term.
} 
Table 9

Robustness Checks

\begin{tabular}{|c|c|c|c|c|c|}
\hline & \multicolumn{3}{|c|}{ Add future food price } & \multicolumn{2}{|c|}{ Add interactions } \\
\hline & 1-year & 2-year & Both & $\begin{array}{l}\text { Food price } \times \\
\text { controls }\end{array}$ & $\begin{array}{l}\mathrm{DF} \times \text { county } \\
\text { fixed effects }\end{array}$ \\
\hline \multicolumn{6}{|c|}{ Dependent variable: body mass index } \\
\hline Food price & $\begin{array}{l}-0.18 \\
(0.08) * *\end{array}$ & $\begin{array}{l}-0.18 \\
(0.08) * *\end{array}$ & $\begin{array}{l}-0.18 \\
(0.08) * *\end{array}$ & $\begin{array}{c}-0.30 \\
(0.41)^{\dagger}\end{array}$ & $\begin{array}{l}-0.18 \\
(0.08) * *\end{array}$ \\
\hline Food price lag & $\begin{array}{l}-0.41 \\
(0.19) * *\end{array}$ & $\begin{array}{l}-0.42 \\
(0.19) * *\end{array}$ & $\begin{array}{l}-0.41 \\
(0.20) * *\end{array}$ & $\begin{array}{c}0.51 \\
(0.49)^{\dagger}\end{array}$ & $\begin{array}{l}-0.46 \\
(0.20) * *\end{array}$ \\
\hline $\begin{array}{l}\text { Discount factor } \times \\
\text { food price }\end{array}$ & $\begin{array}{l}0.27 \\
(0.11) * *\end{array}$ & $\begin{array}{l}0.28 \\
(0.12) * *\end{array}$ & $\begin{array}{l}0.28 \\
(0.12) * *\end{array}$ & $\begin{array}{l}0.27 \\
(0.11) * *\end{array}$ & $\begin{array}{l}0.30 \\
(0.12) * *\end{array}$ \\
\hline $\begin{array}{l}\text { Discount factor } \times \\
\text { food price lag }\end{array}$ & $\begin{array}{l}0.61 \\
(0.27) * *\end{array}$ & $\begin{array}{l}0.63 \\
(0.28) * *\end{array}$ & $\begin{array}{l}0.62 \\
(0.28) * *\end{array}$ & $\begin{array}{l}0.60 \\
(0.27) * *\end{array}$ & $\begin{array}{l}0.65 \\
(0.28) * *\end{array}$ \\
\hline $\begin{array}{l}\text { Total food price } \\
\text { effect }\end{array}$ & $\begin{array}{l}-0.59 \\
(0.19) * * *\end{array}$ & $\begin{array}{l}-0.60 \\
(0.19) * * *\end{array}$ & $\begin{array}{l}-0.59 \\
(0.19) * * *\end{array}$ & $\begin{array}{l}0.21 \\
(0.48)^{\dagger}\end{array}$ & $\begin{array}{l}-0.64 \\
(0.20) * * *\end{array}$ \\
\hline $\begin{array}{l}\text { Total interaction } \\
\text { effect }\end{array}$ & $\begin{array}{l}0.89 \\
(0.27) * * *\end{array}$ & $\begin{array}{l}0.90 \\
(0.28) * * *\end{array}$ & $\begin{array}{l}0.90 \\
(0.28) * * *\end{array}$ & $\begin{array}{l}0.86 \\
(0.28) * * *\end{array}$ & $\begin{array}{l}0.95 \\
(0.28) * * *\end{array}$ \\
\hline Food price in $t+1$ & $\begin{array}{c}-0.037 \\
(0.039)\end{array}$ & - & $\begin{array}{c}-0.029 \\
(0.037)\end{array}$ & - & - \\
\hline Food price in $t+2$ & - & $\begin{array}{c}-0.032 \\
(0.026)\end{array}$ & $\begin{array}{r}-0.030 \\
(0.024)\end{array}$ & - & - \\
\hline Demographics & Yes & Yes & Yes & Yes & Yes \\
\hline Human capital & Yes & Yes & Yes & Yes & Yes \\
\hline Labour & Yes & Yes & Yes & Yes & Yes \\
\hline Income & Yes & Yes & Yes & Yes & Yes \\
\hline Risk & Yes & Yes & Yes & Yes & Yes \\
\hline Observations & 62,360 & 61,061 & 61,061 & 63,950 & 63,950 \\
\hline
\end{tabular}

Notes. For notes see Table $8 .{ }^{\dagger}$ Indicates the coefficient estimates for food price and lagged food price and the 'total food price effect' are uninformative in this specification as the overall effects of food prices are spread over all the interactions with the covariates.

begins to emerge between the BMI distributions of the patient and impatient groups, with the overweight, obesity and severe obesity rates becoming 4, 3 and 2 percentage points greater for the impatient group. Figure 5 shows that at a low food price the difference between the BMI distributions of patient and impatient individuals becomes quite pronounced. The rates of overweight, obesity and severe obesity are now 8,5 and 4 percentage points greater for those who are impatient. These are sizeable differences, representing $13 \%, 18 \%$ and $36 \%$ of the overweight, obesity and severe obesity rates of the patient group, respectively.

\subsubsection{Robustness checks and extensions}

We close our investigation of the interaction effect of discount factor and food prices by estimating some additional variants of the fixed effects model using the full sample. Table 9 reports the results from several robustness checks to help further increase our confidence that the results from Table 8 can be considered causal. The first to third columns test for reverse causality between BMI and food prices by controlling for future food price. The first column includes food price in the subsequent year, the second column includes food price in the second subsequent 


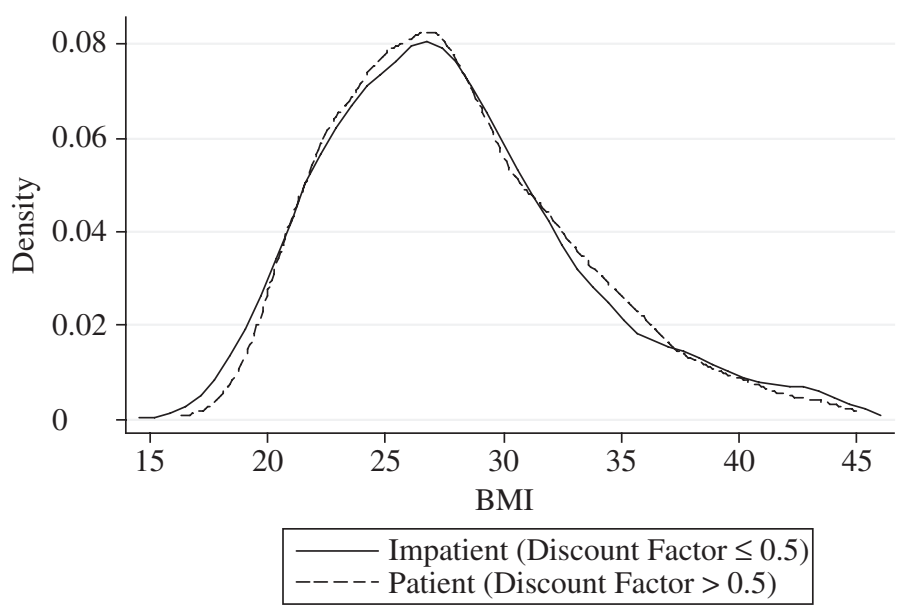

Kernel $=$ Epanechnikov, Bandwidth $=0.9584$

Fig. 3. Body Mass Index (BMI) Distributions by Degree of Patience at Food Price $=\$ 5.50$

Notes. Mean BMI: 28.1 for impatient, 28.2 for patient; $\%$ overweight or obese: $67.8 \%$ for impatient, $68.7 \%$ for patient; $\%$ obese: $30.8 \%$ for impatient, $31.1 \%$ for patient; $\%$ severely obese: $11.7 \%$ for impatient, $11.0 \%$ for patient.

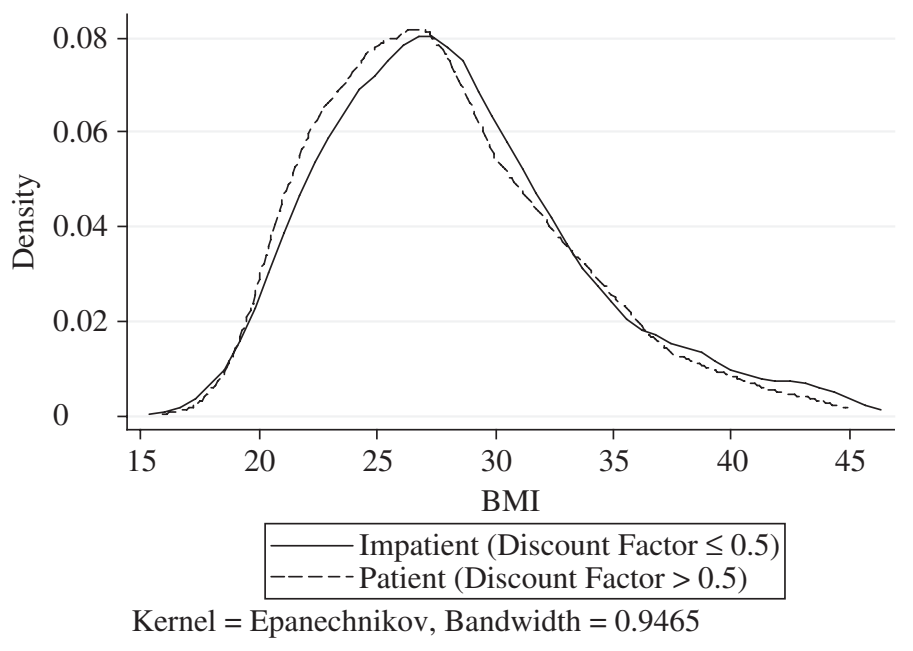

Fig. 4. Body Mass Index (BMI) Distributions by Degree of Patience at Food Price $=\$ 4.00$

Notes. Mean BMI: 28.5 for impatient, 28.0 for patient; $\%$ overweight or obese: $71.3 \%$ for impatient, $67.4 \%$ for patient; $\%$ obese: $33.2 \%$ for impatient, $30.2 \%$ for patient; $\%$ severely obese: $12.8 \%$ for impatient, $10.8 \%$ for patient.

year and the third column adds both of these leads. ${ }^{25}$ If future food prices predict contemporaneous BMI conditional on current food prices, the BMIs of a city's residents likely influence the market price of food rather than the other way around. The fourth column of Table 9 controls for interactions of food prices with all of the other covariates

25 As we have ACCRA COLI data up to 2008, adding two leads does not require us to drop any observations.

(C) 2014 Royal Economic Society. 


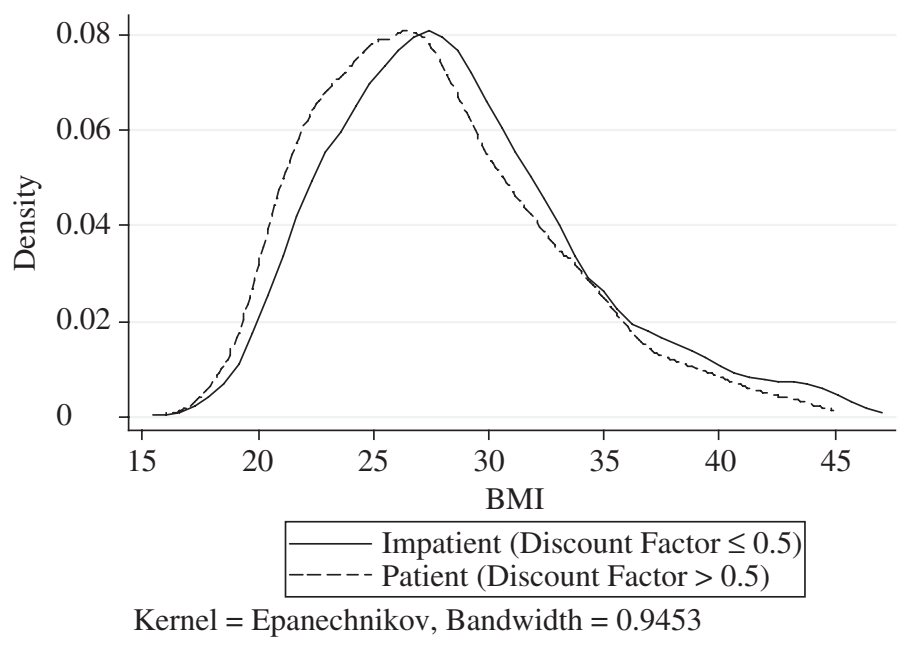

Fig. 5. Body Mass Index (BMI) Distributions by Degree of Patience at Food Price $=\$ 2.50$

Notes. Mean BMI: 29.0 for impatient, 27.8 for patient; \% overweight or obese: $74.0 \%$ for impatient, $65.6 \%$ for patient; $\%$ obese: $35.4 \%$ for impatient, $30.0 \%$ for patient; $\%$ severely obese: $13.9 \%$ for impatient, $10.2 \%$ for patient.

in the model, addressing the possible concern that estimated heterogeneity by time preference might actually reflect heterogeneity by characteristics that are correlated with time preference, such as income and education. Finally, the fifth column controls for interactions of discount factor with county fixed effects. This tests for the possibility that the estimated effect of the interaction of discount factor and food price could simply reflect heterogeneous effects of patience on BMI across geographic regions. As shown in Table 9, the estimates of interest remain very similar to those from Table 8 in all these robustness checks. Additionally, future food prices are not statistically associated with BMI, so there is no evidence of reverse causality. ${ }^{26}$

Finally, we address the potential concern that the food basket used to compute market prices contains both healthy and unhealthy items, whereas the rise in obesity may be the result of cheaper junk food rather than lower across-the-board food prices. We divide the 16 food items into three categories: fruits/vegetables (lettuce, bananas, potatoes, peas, peaches and corn), grocery meats (steak, beef, chicken, sausage, eggs, tuna) and other foods (white bread, cereal and the three restaurant meals). The fruits/ vegetables category contains the most unambiguously healthy foods, so one might expect their prices - and the interaction of their prices with discount factor - to have little or no effect on BMI. In contrast, the 'other foods' category contains items that are either high in starchy carbohydrates, fats, or both and therefore could be considered the most unambiguously unhealthy. Their price effects may therefore be the strongest. The 'grocery meats' category is perhaps in between the other two categories in terms of healthfulness, as they are relatively calorie-dense but high in protein and low in carbohydrates.

\footnotetext{
${ }^{26}$ In unreported regressions, we repeated the falsification exercises with height and the other health conditions as the dependent variables and the full set of controls. Neither discount factor nor its interaction with food prices was ever statistically significant.
} 
Table 10

Multiple Food Categories

(1)

Dependent variable: body mass index

Fruit/vegetable price

$-0.02$

0.32

Fruit/vegetable price lag

$-0.01$

$(0.22)$

Meat price

Meat price lag

Other food price

Other food price lag

$-0.26$

$(0.01)^{*}$

Discount factor $\times$ fruit/vegetable price

$-0.38$

$(0.14)^{*}$

Discount factor $\times$ fruit/vegetable price lag

$-0.13$

$(0.12) * * *$

Discount factor $\times$ meat price

$-0.11$

$(0.12)$

Discount factor $\times$ meat price 1

$-0.44$

0.02

$(0.30)$

$(0.32)$

0.40

$(0.02)$

Discount factor $\times$ other food price

0.61

0.16

$(0.21) *$

Discount factor $\times$ other food price lag

$(0.19) * * *$

Total fruit/vegetable price effect

0.30

$(0.18)$

Total meat price effect

Total other food price effect

Total discount factor $\times$ fruit/vegetable price effect

$-0.28$

$(0.35)$

Total discount factor $\times$ meat price effect

Total discount factor $\times$ other food price effect

$-0.51$

$(0.14) *$

Demographics

Human capital

$-0.55$

$(0.15) * * *$

0.42

$(0.50)$

0.77

$(0.21) * *$
$(0.23) * * *$

Yes

Labour

Yes

Yes

Income

Risk

Observations

Yes

Yes

63,950

Note. For notes see Table 8 .

Table 10 reports the results from estimating a fixed effects regression with prices for each of these three different types of foods, along with their interactions with discount factor:

$$
\begin{aligned}
\text { BMI }_{i c t}= & \alpha_{0}+\boldsymbol{\alpha}_{11} \mathbf{X}_{i c t}+\alpha_{12} \mathbf{X}_{i c, t-1}+\alpha_{21} \text { PFRVEG }_{c t}+\alpha_{22} \text { PFRVEG }_{c, t-1} \\
& +\alpha_{31}\left(D F 1_{i c} \times \text { PFRVEG }_{c t}\right)+\alpha_{32}\left(D F 1_{i c} \times P R V E G_{c, t-1}\right)+\alpha_{41} \text { PMEAT }_{c t} \\
& +\alpha_{42} \text { PMEAT }_{c, t-1}+\alpha_{51}\left(D F 1_{i} \times P M E A T_{c t}\right)+\alpha_{52}\left(D F 1_{i c} \times \text { PMEAT }_{c, t-1}\right) \\
& +\alpha_{61} \text { POTHER }_{c t}+\alpha_{62} \text { POTHER }_{c, t-1}+\alpha_{7,1}\left(D F 1_{i c} \times P O T H E R_{c t}\right) \\
& +\alpha_{7,2}\left(D F 1_{i c} \times \text { POTHER }_{c, t-1}\right)+\alpha_{8,1} P N F_{c t}+\alpha_{8,2} P N F_{c, t-1}+\mu_{i}+\tau_{t}+\varepsilon_{i c t},
\end{aligned}
$$

where $\mathbf{X}$ denotes the set of demographic, human capital, labour and income controls and PFRVEG, PMEAT and POTHER are the prices of fruits/vegetables, meats and other foods. The results are as expected. We find no evidence that fruit/vegetable price or its interaction with discount factor influence BMI. The total effects of meat prices, other food prices and their interactions with discount factor are all significant at the $10 \%$ level or better and have the same signs as the earlier estimates using the entire basket. However, both the price and interaction effects are larger in magnitude for other foods than meats, consistent with our assumption that the foods in the 'other' category are the least healthy.

\subsection{Time-inconsistent Discounting and BMI}

The final subsection of our empirical analysis provides a preliminary attempt to determine the degree to which the observed relationship between time preference and (C) 2014 Royal Economic Society. 
BMI reflects rational intertemporal substitution as opposed to self-control problems. As described in Section 2, the 2006 NLSY contains two intertemporal discounting questions, one over a monthly interval and the other over an annual interval, allowing us to fit the $\beta$ (present-bias) and $\delta$ (long-run patience) parameters of a quasihyperbolic specification. The three-period theoretical model predicted that both $\beta$ and $\delta$ should influence BMI. We test these predictions by replacing the univariate measure of discounting from our previous regressions with both $\beta$ and $\delta$. The main BMI regression takes the form

$$
B M I_{i}=\theta_{0}+\theta_{1} \beta_{i}+\theta_{2} \delta_{i}+\theta_{3} \mathbf{X}_{i}+\varepsilon_{i},
$$

while the fixed effects model using the full sample that adds prices and the interactions of food prices with $\beta$ and $\delta$ is

$$
\begin{aligned}
B M I_{i c t}= & \theta_{0}+\boldsymbol{\theta}_{11} \mathbf{X}_{i c t}+\boldsymbol{\theta}_{12} \mathbf{X}_{i c, t-1}+\theta_{21} \text { PFOOD }_{c t}+\theta_{22} \text { PFOOD }_{c, t-1} \\
& +\theta_{31}\left(\beta_{i c} \times \text { PFOOD }_{c t}\right)+\theta_{32}\left(\beta_{i c} \times \text { PFOOD }_{c, t-1}\right)+\theta_{41}\left(\delta_{i c} \times \text { PFOOD }_{c t}\right) \\
& +\theta_{42}\left(\delta_{i c} \times \text { PFOOD }_{c, t-1}\right)+\theta_{51} \text { PNF }_{c t}+\theta_{52} P F_{c, t-1}+\mu_{i}+\tau_{t}+\varepsilon_{i c t} .
\end{aligned}
$$

To conserve space, we only report the results from the regressions with all the control variables, along with those evaluating heterogeneity by gender, race and food category. We have, however, re-estimated all the robustness checks and falsification tests from Tables 5-10 replacing discount factor with $\beta$ and $\delta$ and verified that our findings are not sensitive to specification. These results are available upon request.

The results in the first column of Table 11 show that both present-bias $\beta$ and longrun patience $\delta$ are statistically significant and negatively associated with BMI. Present bias and long-run impatience therefore both separately influence weight. The magnitudes imply that a $1 \mathrm{SD}$ increase in $\beta$ (decrease in present bias) reduces $\mathrm{BMI}$ by 0.2 units or 1.3 pounds at the sample mean height, while a SD increase in $\delta$ (timeconsistent patience) reduces weight by $0.17 \mathrm{BMI}$ units or 1.1 pounds. The second and third columns reveal that the coefficient on $\beta$ is negative and statistically significant for women but $\delta$ is not significant, whereas the reverse pattern holds for men. This suggests that the relationship between intertemporal preferences and BMI is driven by

Table 11

Time Inconsistency and Body Mass Index (BMI)

\begin{tabular}{lccccc}
\hline \hline & All & Women & Men & White & Non-white \\
\hline Dependent variable: $B M I$ & & & & & \\
Beta & -0.98 & -1.36 & -0.60 & -1.16 & 0.23 \\
& $(0.46)^{* *}$ & $(0.62)^{* *}$ & $(0.67)$ & $(0.53)^{* *}$ & $(0.71)$ \\
Delta & -0.51 & -0.23 & -0.84 & -0.58 & -0.24 \\
& $(0.25)^{* *}$ & $(0.37)$ & $(0.35)^{* *}$ & $(0.32)^{*}$ & $(0.35)$ \\
Demographics & Yes & Yes & Yes & Yes & Yes \\
Human capital & Yes & Yes & Yes & Yes & Yes \\
Labour & Yes & Yes & Yes & Yes & Yes \\
Income & Yes & Yes & Yes & Yes & Yes \\
Risk & Yes & Yes & Yes & 3,894 & 2,088 \\
Observations & 5,982 & 2,989 & 2,993 & & \\
& & &
\end{tabular}

Notes. For notes see Table 5 .

(C) 2014 Royal Economic Society. 
Table 12

Interaction of Beta and Delta with Food Prices

\begin{tabular}{|c|c|c|c|c|}
\hline & \multicolumn{2}{|c|}{ Single price } & \multicolumn{2}{|c|}{ Multiple prices } \\
\hline \multicolumn{5}{|l|}{ Dependent variable: body mass index } \\
\hline Beta & - & & - & \\
\hline Delta & - & & - & \\
\hline Food price & -0.44 & $(0.19) * *$ & - & \\
\hline Food price lag & -0.61 & $(0.36)^{*}$ & - & \\
\hline Beta $\times$ food price & 0.52 & $(0.22) * *$ & - & \\
\hline Beta $\times$ food price lag & 0.38 & $(0.37)$ & - & \\
\hline Delta $\times$ food price & 0.005 & $(0.114)$ & - & \\
\hline Delta $\times$ food price lag & 0.34 & $(0.18) *$ & - & \\
\hline Fruit/vegetable price & - & & 0.07 & $(0.35)$ \\
\hline Fruit/vegetable price lag & - & & 0.39 & $(0.42)$ \\
\hline Beta $\times$ fruit/vegetable price & - & & -0.07 & $(0.32)$ \\
\hline Beta $\times$ fruit/vegetable price lag & - & & -0.36 & $(0.39)$ \\
\hline Delta $\times$ fruit/vegetable price & - & & -0.14 & $(0.23)$ \\
\hline Delta $\times$ fruit/vegetable price lag & - & & -0.06 & $(0.24)$ \\
\hline Meat price & - & & -0.03 & $(0.03)$ \\
\hline Meat price lag & - & & -0.52 & $(0.26) * *$ \\
\hline Beta $\times$ meat price & - & & 0.05 & $(0.04)$ \\
\hline Beta $\times$ meat price lag & - & & 0.40 & $(0.24) *$ \\
\hline Delta $\times$ meat price & - & & -0.01 & $(0.02)$ \\
\hline Delta $\times$ meat price lag & - & & 0.23 & $(0.15)$ \\
\hline Other food price & - & & -0.80 & $(0.23) * * *$ \\
\hline Other food price lag & - & & -0.03 & $(0.24)$ \\
\hline Beta $\times$ other food price & - & & 0.85 & $(0.22) * * *$ \\
\hline Beta $\times$ other food price lag & - & & -0.09 & $(0.24)$ \\
\hline Delta $\times$ other food price & - & & 0.14 & $(0.15)$ \\
\hline Delta $\times$ other food price lag & - & & 0.10 & $(0.12)$ \\
\hline Total food price effect & -1.05 & $(0.36) * * *$ & - & \\
\hline Total food price $\times$ beta effect & 0.89 & $(0.37) * * *$ & - & \\
\hline Total food price $\times$ delta effect & 0.34 & $(0.21)$ & - & \\
\hline Total fruit/vegetable price effect & - & & 0.46 & $(0.62)$ \\
\hline Total fruit/vegetable price $\times$ beta effect & - & & -0.43 & $(0.56)$ \\
\hline Total fruit/vegetable price $\times$ delta effect & - & & -0.20 & $(0.39)$ \\
\hline Total meat price effect & - & & -0.55 & $(0.26) * *$ \\
\hline Total meat price $\times$ beta effect & - & & 0.45 & $(0.24) *$ \\
\hline Total meat price $\times$ delta effect & - & & 0.22 & $(0.16)$ \\
\hline Total other food price effect & - & & -0.83 & $0.30 * * *$ \\
\hline Total other food price $\times$ beta effect & - & & 0.75 & $(0.31) * *$ \\
\hline Total other food price $\times$ delta effect & - & & 0.24 & $(0.18)$ \\
\hline Observations & 63,950 & & 63,950 & \\
\hline
\end{tabular}

Notes. All controls are included. For other notes see Table 8.

present bias for females but time-consistent impatience for males. Stratifying by race shows that both $\beta$ and $\delta$ predict the BMI of whites but there is no evidence that either influence the weight of non-whites.

Table 12 presents the results for the interaction of $\beta$ and $\delta$ with food prices. The first column uses the fixed effects approach with one food price variable and the second column uses the fixed effects model with multiple food categories. We focus our discussion on the 'total effects' of the interactions of $\beta$ and $\delta$ with food prices. These are simply the sum of the estimates for the contemporaneous and lagged interaction terms. The interaction of $\beta$ and food prices is positive and statistically significant, while the interaction of $\delta$ and food prices is also positive but marginally insignificant. When (C) 2014 Royal Economic Society. 
multiple food categories are used, the interactions of $\beta$ with meat and 'other food' prices both significantly increase BMI, while the interactions of $\delta$ with meat and 'other food' prices are also positively associated with BMI but are insignificant. In all, the evidence that time-inconsistent individuals respond more strongly to food prices is therefore clearer than the evidence regarding the interaction of time-consistent impatience and food prices.

\section{Conclusion}

This study investigates the connection between time preferences, economic incentives and BMI. Our theoretical model predicts that greater impatience increases BMI and might strengthen individuals' responses to food prices. We test these predictions using the NLSY matched with local price data from C2ER. Impatience is associated with BMI and the probabilities of being overweight and obese across a wide range of specifications. Interacting discount factor with food prices reveals that the gap between the weights of impatient and patient individuals is larger in counties with lower food prices. Finally, we consider time-inconsistent quasi-hyperbolic discounting. Both present bias $(\beta)$ and the long-run discount factor $(\delta)$ are negatively correlated with BMI and their interactions with food prices are positively correlated with BMI, though only the interaction with $\beta$ is statistically significant.

Our study aims to combine two strands of the literature on the economic causes of obesity in an effort to help explain why the BMI distribution has not only shifted to the right but also thickened in the right tail. The majority of the literature focuses on the influence of economic factors such as food prices on weight. While society-wide changes in economic incentives can explain the shift to the right in the BMI distribution, they alone cannot explain why individuals in the right tail of the distribution have experienced the largest weight gains while others in the left tail have not gained any weight. Another portion of the literature links time preference to BMI, but has left unclear whether this link can help to explain the rise in obesity as the best available evidence suggests time preferences are reasonably stable. We propose that incentives and impatience interact to explain the changes in the BMI distribution in recent decades. As economic factors lower the opportunity cost of food consumption, impatient individuals gain weight while the most patient individuals do not. Mean BMI therefore rises but the rise is concentrated among a subset of the population. We provide a preliminary test of this theory in the context of food prices.

Our results suggest several potentially interesting directions for future research. First, future work should examine whether the interaction of time preference with other economic incentives, such as those that affect the opportunity cost of physical activity rather than eating, also predict BMI. Future research should also test our theory across a broader time period, as our data only span two of the nearly four decades of the sharp rise in obesity. Further study of how the effects differ across different demographic groups could also have interesting implications. For instance, from 1960 to 1994 the rise in obesity was similar for men and women but from 1999 to 2010 obesity prevalence only increased for men (Flegal et al., 1998; Ogden et al., 2012). For men, BMI is more strongly correlated with the time-consistent long-run discount factor than it is with the timeinconsistent present bias discount factor. For women, the opposite is true. If these 
results prove to be generalisable, time-consistent patience may be more relevant for the recent portion of the rise in obesity than it was for the earlier decades but the reverse may be true for present-bias.

It is also worth noting that the theory of rational addiction makes a similar prediction to ours about the interaction effect: addicts who are more patient are less responsive to current prices (Becker et al., 1991). Townsend (1987) and Chaloupka (1991) test this prediction with data on cigarette consumption, but with proxies for patience (class and education, respectively). Though not in the context of a model of rational addiction, our tests using the interaction of food prices and individual time preferences are the first such tests of this prediction utilising a direct measure of patience rather than indirect proxies.

Our article also provides the first attempt to model quasi-hyperbolic discounting parameters $\beta$ and $\delta$ explicitly and test their separate influences on BMI and obesity. The results suggest that the intertemporal trade-offs that determine body weight are at least partly due to time-inconsistent discounting, which has potential policy implications. The standard rationale for policies aimed at curbing obesity comes from externalities associated with obesity, such as medical expenditures paid by the government or other members of a private insurance pool. However, Bhattacharya and Sood (2011) argue that there are no externalities from obesity, that is, that the costs of obesity are paid for by the obese person himself or herself through either out-of-pocket medical costs or foregone wages. Time inconsistency could provide a different rationale for interventions that move more of the costs of overeating into the present period, such as taxes on unhealthy foods. Such a conclusion depends on how we ought to conduct welfare analysis under time-inconsistent preferences. One argument is that we should treat the present bias as a 'mistake' or a type of market/behavioural failure and the social planner should maximise using a welfare function that does not include $\beta$. This is the approach taken by Gruber and Koszegi (2001), O'Donoghue and Rabin (2006) and Heutel (2011). Others, for example, Bernheim and Rangel (2009), propose a different set of welfare criteria and do not find that present bias justifies policy intervention in all cases.

Georgia State University and NBER

University of North Carolina at Greensboro and NBER

Federal Trade Commission

Submitted: 5 September 2012

Accepted: 25 November 2013

Additional Supporting Information may be found in the online version of this article:

\section{Data S1.}

\section{References}

Anderson, L. and Mellor, J. (2008). 'Predicting health behaviors with an experimental measure of risk preference', Journal of Health Economics, vol. 27(5), pp. 1260-74.

Becker, G., Grossman, M. and Murphy, K. (1991). 'Rational addiction and the effect of price on consumption', American Economic Review, vol. 81(2), pp. 237-41. 
Bernheim, B. and Rangel, A. (2009). 'Beyond revealed preference: choice-theoretic foundations for behavioral welfare economics', Quarterly Journal of Economics, vol. 124(1), pp. 51-104.

Bhattacharya, J. and Sood, N. (2011). 'Who pays for obesity?' Journal of Economic Perspectives, vol. 25(1), pp. 139-58.

Borghans, L. and Golsteyn, B. (2006). 'Time discounting and the body mass index: evidence from the Netherlands', Economics and Human Biology, vol. 4(1), pp. 29-61.

Cadena, B. and Keys, B. (2011). 'Human capital and the lifetime costs of impatience', Available at SSRN: http://ssrn.com/abstract=1674068 or http://dx.doi.org/10.2139/ssrn.1674068 (last accessed: 19 March 2014).

Cawley, J. (1999). 'Rational addiction, the consumption of calories, and body weight', Ph.D. dissertation, University of Chicago, Chicago, IL.

Chabris, C., Laibson, D., Morris, C., Schuldt, J. and Taubinsky, D.(2008). 'Individual laboratory-measured discount rates predict field behavior', Journal of Risk and Uncertainty, vol. 37(2-3), pp. 237-69.

Chaloupka, F. (1991). 'Rational addictive behavior and cigarette smoking', Journal of Political Economy, vol. 99 (4), pp. 722-42.

Chou, S., Grossman, M. and Saffer, H. (2004). 'An economic analysis of adult obesity: results from the behavioral risk factor surveillance system', Journal of Health Economics, vol. 23(3), pp. 565-87.

Chung, C. and Myers, S.L. (1999). 'Do the poor pay more for food? An analysis of grocery store availability and food price disparities', Journal of Consumer Affairs, vol. 33(2), pp. 276-96.

Coller, M. and Williams, M. (1999). 'Eliciting individual discount rates', Experimental Economics, vol. 2(2), pp. 107-27.

Courtemanche, C. and Carden, A. (2011). 'Supersizing supercenters? The impact of Walmart Supercenters on body mass index and obesity', Journal of Urban Economics, vol. 69(2), pp. 165-81.

Cutler, D., Glaeser, E. and Shapiro, J. (2003). 'Why have Americans become more obese?', Journal of Economic Perspectives, vol. 17(3), pp. 93-118.

DellaVigna, S. and Paserman, M.D. (2005). 'Job search and impatience', Journal of Labor Economics, vol. 23(3), pp. 527-88.

Finkelstein, E., Fiebelkorn, I. and Wang, G. (2003). 'National medical spending attributable to overweight and obesity: how much, and who's paying?' Health Affairs, Web Exclusives: pp. W219-26.

Flegal, K., Carroll, M., Kuczmarski, R. and Johnson, C. (1998). 'Overweight and obesity in the United States: prevalence and trends, 1960-1994', International Journal of Obesity, vol. 22(1), pp. 39-47.

Flegal, K., Graubard, B., Williamson, D. and Gail, M. (2005). 'Excess deaths associated with underweight, overweight, and obesity', Journal of the American Medical Association, vol. 293(15), pp. 1861-67.

Goldman, D., Lakdawalla, D. and Zheng, Y. (2011). 'Food prices and the dynamics of body weight', in (M. Grossman and N. Mocan, eds.), Economic Aspects of Obesity, pp. 65-90, Chicago IL: University of Chicago Press.

Gruber, J. and Koszegi, B. (2001). 'Is addiction "rational”? Theory and evidence', Quarterly Journal of Economics, vol. 116(4), pp. 1261-303.

Heutel, G. (2011). 'Optimal policy instruments for externality-producing durable goods under time inconsistency', Working Paper 17083, National Bureau of Economic Research.

Ikeda, S., Kang, M. and Ohtake, F. (2010). 'Hyperbolic discounting, the sign effect, and the body mass index', Journal of Health Economics, vol. 29(2), pp. 268-84.

Johnson, M.W. and Bickel, W.K. (2002). 'Within-subject comparison of real and hypothetical money rewards in delay discounting', Journal of the Experimental Analysis of Behavior, vol. 77(2), pp. 129-46.

Kirby, K. and Marakovic, N. (1995). 'Modeling myopic decisions: evidence for hyperbolic delaydiscounting within subjects and amounts', Organizational Behavior and Human Decision Processes, vol. 64 (1), pp. 22-30.

Komlos, J., Smith, P. and Bogin, B. (2004). 'Obesity and the rate of time preference: is there a connection?', Journal of Biosocial Science, vol. 36(2), pp. 209-19.

Laibson, D. (1997). 'Golden eggs and hyperbolic discounting', Quarterly Journal of Economics, vol. 112(2), pp. $443-77$.

Lakdawalla, D. and Philipson, T. (2009). 'The growth of obesity and technological change', Economics $\mathcal{E}^{\circ}$ Human Biology, vol. 7(3), pp. 283-93.

Lakdawalla, D., Philipson, T. and Bhattacharya, J. (2005). 'Welfare-enhancing technological change and the growth of obesity', American Economic Review Papers and Proceedings, vol. 95(2), pp. 253-57.

Loewenstein, G. (1988). 'Frames of mind in intertemporal choice', Management Science, vol. 34(2), pp. 20014.

Madden, G.J., Begotka, A.M., Raiff, B.R. and Kastern, L.L. (2003). 'Delay discounting of real and hypothetical rewards', Experimental and Clinical Psychopharmacology, vol. 11(2), pp. 139-45.

McAlvanah, P. (2010). 'Subadditivity, patience, and utility: the effects of dividing time intervals', Journal of Economic Behavior and Organization, vol. 76(2), pp. 325-37.

Meier, S. and Sprenger, C. (2010). 'Stability of time preferences', Working Paper 4756, Institute for the Study of Labour (IZA). 
National Center of Health Statistics (2008). 'Prevalence of overweight, obesity and extreme obesity among adults: United States, trends 1976-80 through 2005-2006', http://www.cdc.gov/nchs/data/hestat/ overweight/overweight_adult.pdf (last accessed: 19 March 2014).

National Institute of Diabetes and Digestive and Kidney Diseases (2008). 'Longitudinal assessment of bariatric surgery (LABS)', No. 04-5573, NIH publication.

O'Donoghue, T. and Rabin, M. (2006). 'Optimal sin taxes', Journal of Public Economics, vol. 90(10-11), pp. $1825-49$.

Ogden, C., Carroll, M., Kit, B. and Flegal, K. (2012). 'Prevalence of obesity in the United States, 2009-2010', NCHS Data Brief no. 82, US Department of Health and Human Services.

Percoco, M. and Nijkamp, P. (2009). 'Estimating individual rates of discount: a meta-analysis', Applied Economics Letters, vol. 16(12), pp. 1235-39.

Phelps, E.S. and Pollak, R. (1968). 'On second-best national saving and game-equilibrium growth', Review of Economic Studies, vol. 35(2), pp. 185-99.

Philipson, T. and Posner, R. (2003). 'The long-run growth in obesity as a function of technological change', Perspectives in Biology and Medicine, vol. 46(3), pp. S87-107.

Royer, H., Stehr, M. and Snydor, J. (2012). 'Incentives, commitments and habit formation in exercise: evidence from a field experiment with workers at a fortune-500 company', NBER Working Paper 18580.

Ruhm, C. (2012). 'Understanding overeating and obesity', Journal of Health Economics, vol. 31 (6), pp. $781-96$.

Scharff, R. (2009). 'Obesity and hyperbolic discounting: evidence and implications', Journal of Consumer Policy, vol. 32(1),pp. 3-21.

Seeyave, D., Coleman, S., Appugliese, D., Corwyn, R., Bradley, R., Davidson, N., Kaciroti, N. and Lumeng, J. (2009). 'Ability to delay gratification at age 4 years and risk of oveweight at age 11 years', Archives of Pediatrics and Adolescent Medicine, vol. 163(4), pp. 303-8.

Shelley, M. (1993). 'Outcome signs, question frames, and discount rates', Management Science, vol. 39(7), pp. 806-15.

Simpson, C. and Vuchinich, R. (2000). 'Reliability of a measure of temporal discounting', Psychological Record, vol. 50(1), pp. 3-16.

Smith, P., Bogin, B. and Bishai, D. (2005). 'Are time preference and body mass index associated? Evidence from the National Longitudinal Survey of Youth', Economics and Human Biology, vol. 3(2), pp. 259-70.

Sturm, R. (2002). 'The effects of obesity, smoking, and drinking on medical problems and costs', Health Affairs, vol. 21(2), pp. 245-53.

Sutter, M., Kocher, M., Rutzler, D. and Trautmann, S. (2013). 'Impatience and uncertainty: experimental decisions predict adolescents' field behavior', American Economic Review, vol. 103(1), pp. 510-31.

Townsend, J. (1987). 'Cigarette tax, economic welfare and social class patterns of smoking', Applied Economics, vol. $19(3)$, pp. 355-65.

Ubfal, D., 2012. 'How general are time preferences? Eliciting good-specific discount rates', Discussion Paper 6774, Institute for the Study of Labour (IZA).

US Department of Health and Human Services (2001). 'The surgeon general's call to action to prevent and decrease overweight and obesity', available at, http://www.ncbi.nlm.nih.gov/books/NBK44206/ (last accessed 19 March 2014).

Van der Pol, M. (2011). 'Health, education and time preference', Health Economics, vol. 20(8), pp. 917-29.

Weller, R., Cook, E., Avsar, K. and Cox, J. (2008). 'Obese women show greater delay discounting than healthyweight women', Appetite, vol. 51(3), pp. 563-9.

Zhang, L. and Rashad, I. (2008). 'Obesity and time preference: the health consequences of discounting the future', Journal of Biosocial Science, vol. 40(1), pp. 97-113. 